\title{
Effective dynamic prediction of air conditions within car cabin via bilateral analyses of theoretical models and artificial neural networks
}

\author{
Daniel KRISTANTO* and Thananchai LEEPHAKPREEDA* \\ *School of Manufacturing Systems and Mechanical Engineering, \\ Sirindhorn International Institute of Technology, Thammasat University \\ P.O. Box 22, Thammasat-Rangsit Post Office, \\ Pathum Thani, 12120, Thailand \\ E-mail: thanan@siit.tu.ac.th
}

Received: 15 October 2017; Revised: 23 May 2018; Accepted: 25 June 2018

\begin{abstract}
Dynamic prediction of air conditions within a car cabin is significant to technology design and usage for thermal comfort, air quality, and energy consumption of vehicles. In this paper, theoretical models are completely derived from mass and energy balances of moist air and carbon dioxide from an outdoor environment via vehicle envelope to car cabin. However, it is demanding to determine genuine modeling hypothesis and/or physical properties of car cabins for accurate prediction. Regardless of those requirements, artificial neural networks can be applied as universal models, which are derived from numbers of input/output data from real dynamic systems. Without any experimental efforts, the input/output data is generated from the theoretical models under various conditions. A few input/output data from experiments are combined for making prediction close to actual behaviors. With bilateral analyses, the artificial neural networks are trained effectively to simulate dynamic behaviors of air, moisture, and carbon dioxide within a car cabin. This viability of the proposed methodology is confirmed by that the averaged coefficients of determination to the perfect prediction under parking and driving conditions of a sedan car are $\mathrm{R}^{2}=0.9394$, and $\mathrm{R}^{2}=0.9314$, respectively. The numbers of experimental data for training are $3.5 \%$ of total numbers of training data.
\end{abstract}

Keywords : Energy and mass transfer, Mathematical modeling, Air conditions, Car cabin, Driving, Parking, Artificial neural network

\section{Nomenclature}

Symbol Definition

$A_{e} \quad$ Area of envelope $\left(\mathrm{m}^{2}\right)$

$A_{f} \quad$ Area of floor $\left(\mathrm{m}^{2}\right)$

$A_{w} \quad$ Area of windshield $\left(\mathrm{m}^{2}\right)$

C C Carbon dioxide concentration of cabin (ppm)

$C_{a} \quad$ Ambient carbon dioxide concentration (ppm)

$\dot{E}_{i} \quad$ Energy with which air enters car cabin (W)

$\dot{E}_{o} \quad$ Energy with which air leaves car cabin (W)
Symbol Definition

$T_{w} \quad$ Temperature of windshield $\left({ }^{\circ} \mathrm{C}\right)$

$V \quad$ Volume of car cabin $\left(\mathrm{m}^{3}\right)$

$V_{e, i} \quad$ Volume of insulator in envelope $\left(\mathrm{m}^{3}\right)$

$T_{e, s} \quad$ Volume of steel in envelope $\left(\mathrm{m}^{3}\right)$

$V_{e, c} \quad$ Volume of cover in envelope $\left(\mathrm{m}^{3}\right)$

$V_{f, i} \quad$ Volume of insulator in floor $\left(\mathrm{m}^{3}\right)$

$V_{f, s} \quad$ Volume of steel in floor $\left(\mathrm{m}^{3}\right)$ 


\begin{tabular}{|c|c|c|c|}
\hline$G$ & Irradiation $\left(\mathrm{W} / \mathrm{m}^{2}\right)$ & $V_{w}$ & Volume of windshield $\left(\mathrm{m}^{3}\right)$ \\
\hline$G_{\alpha}$ & Absorbed solar radiation $\left(\mathrm{W} / \mathrm{m}^{2}\right)$ & $W$ & $\begin{array}{l}\text { Heat generation rate due to electric } \\
\text { appliances (W) }\end{array}$ \\
\hline$G_{r}$ & Reflected solar radiation $\left(\mathrm{W} / \mathrm{m}^{2}\right)$ & $b$ & Bias of output variable \\
\hline$G_{\tau}$ & Transmitted solar radiation $\left(\mathrm{W} / \mathrm{m}^{2}\right)$ & $b_{j}$ & Bias of hidden-layer variable $j$ \\
\hline$G_{r, g}$ & Solar radiation reflected by ground $\left(\mathrm{W} / \mathrm{m}^{2}\right)$ & $C$ & Specific heat of dry air $\left(\mathrm{J} / \mathrm{kg}^{\circ} \mathrm{C}\right)$ \\
\hline$G_{\alpha, e}$ & Solar radiation absorbed by envelope $\left(\mathrm{m}^{2}\right)$ & $C_{C}$ & Specific heat of cover $\left(\mathrm{J} / \mathrm{kg}^{\circ} \mathrm{C}\right)$ \\
\hline$G_{\alpha, f}$ & Solar radiation absorbed by floor $\left(\mathrm{W} / \mathrm{m}^{2}\right)$ & $C_{i}$ & Specific heat of insulator $\left(\mathrm{J} / \mathrm{kg}^{\circ} \mathrm{C}\right)$ \\
\hline$G_{\alpha, w}$ & Solar radiation absorbed by windshield $\left(\mathrm{W} / \mathrm{m}^{2}\right)$ & $C_{s}$ & Specific heat of steel $\left(\mathrm{J} / \mathrm{kg}^{\circ} \mathrm{C}\right)$ \\
\hline$H$ & Hidden-layer variables & $C_{v}$ & Specific heat of water vapor $\left(\mathrm{J} / \mathrm{kg}^{\circ} \mathrm{C}\right)$ \\
\hline$\dot{H}$ & $\begin{array}{l}\text { Human humidity generation rate per person } \\
(\mathrm{kg} / \mathrm{s})\end{array}$ & $C_{w}$ & Specific heat of windshield $\left(\mathrm{J} / \mathrm{kg}^{\circ} \mathrm{C}\right)$ \\
\hline$I$ & Input variables & $h$ & Heat transfer coefficient $\left(\mathrm{W} / \mathrm{m}^{2 \circ} \mathrm{C}\right)$ \\
\hline$I_{m}$ & Identity matrix & $i$ & Index of input variables \\
\hline$J$ & Jacobian matrix & $j$ & Index of hidden-layer variables \\
\hline$\dot{K}$ & $\begin{array}{l}\text { Human carbon dioxide generation rate per } \\
\text { person }(\mathrm{kg} / \mathrm{s})\end{array}$ & $k$ & Iteration index \\
\hline$L_{e, c}$ & Thickness of cover in envelope (m) & $l$ & Summation index \\
\hline$L_{e, i}$ & Thickness of insulator in envelope (m) & $k_{e, c}$ & $\begin{array}{l}\text { Thermal conductivity of cover } \\
\text { in envelope }\left(\mathrm{W} / \mathrm{m}^{\circ} \mathrm{C}\right)\end{array}$ \\
\hline$L_{e, s}$ & Thickness of steel in envelope (m) & $k_{e, i}$ & $\begin{array}{l}\text { Thermal conductivity of insulator } \\
\text { in envelope }\left(\mathrm{W} / \mathrm{m}^{\circ} \mathrm{C}\right)\end{array}$ \\
\hline$L_{f, i}$ & Thickness of insulator in floor (m) & $k_{e, s}$ & $\begin{array}{l}\text { Thermal conductivity of steel } \\
\text { in envelope }\left(\mathrm{W} / \mathrm{m}^{\circ} \mathrm{C}\right)\end{array}$ \\
\hline$L_{f, s}$ & Thickness of steel in floor (m) & $k_{f, i}$ & $\begin{array}{l}\text { Thermal conductivity of insulator } \\
\text { in floor }\left(\mathrm{W} / \mathrm{m}^{\circ} \mathrm{C}\right)\end{array}$ \\
\hline$\dot{M}$ & $\begin{array}{l}\text { Heat generation rate of human metabolism } \\
\text { person }(\mathrm{W})\end{array}$ & $k_{f, s}$ & $\begin{array}{l}\text { Thermal conductivity of steel } \\
\text { in floor }\left(\mathrm{W} / \mathrm{m}^{\circ} \mathrm{C}\right)\end{array}$ \\
\hline$N$ & Number of occupants & $\dot{m}_{e x}$ & Mass flow rate of exfiltration (kg/s) \\
\hline$N_{i}$ & Number of input variables & $\dot{m}_{f}$ & Mass flow rate of fresh air $(\mathrm{kg} / \mathrm{s})$ \\
\hline$N_{j}$ & Number of hidden-layer variable & $\dot{m}_{i n}$ & Mass flow rate of infiltration (kg/s) \\
\hline$N_{t}$ & Number of training data & $\dot{m}_{r}$ & Mass flow rate of return air $(\mathrm{kg} / \mathrm{s})$ \\
\hline$O$ & Output variable & $\dot{m}_{s}$ & Mass flow rate of supply air $(\mathrm{kg} / \mathrm{s})$ \\
\hline
\end{tabular}


$O_{d} \quad$ Desired output variable

$\dot{Q}_{c, e a} \quad$ Convection heat transfer from envelope to surrounding (W)

$\dot{Q}_{c, e c} \quad$ Convection heat transfer from envelope to car cabin (W)

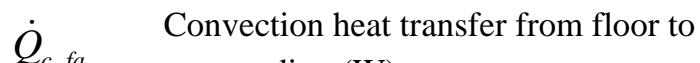
surrounding (W)

$\dot{Q}_{c, f c} \quad$ Convection heat transfer from floor to car cabin (W)

$\dot{Q}_{c, w a} \quad$ Convection heat transfer from windshield to surrounding (W)

$\dot{Q}_{c, w c} \quad$ Convection heat transfer from windshield to $\dot{Q}_{c, w c} \quad$ car cabin (W)

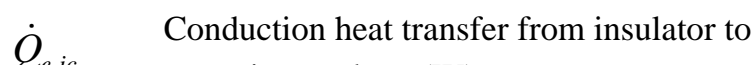
cover in envelope (W)

$\dot{Q} \quad$ Conduction heat transfer from steel to insulator in envelope (W)

$\dot{Q}_{f} \quad$ Conduction heat transfer from steel to insulator in floor (W)

$\dot{Q}_{r, e a} \quad$ Radiation heat transfer from envelope to surrounding (W)

$\dot{Q}_{r, e c} \quad$ Radiation heat transfer from envelope to car cabin (W)

$\dot{Q}_{r, f a} \quad$ Radiation heat transfer from floor to surrounding (W)

$\dot{Q} \quad$ Radiation heat transfer from floor to car cabin (W)

$\dot{Q}_{r, w a} \quad$ Radiation heat transfer from windshield to surrounding (W)

$\dot{Q}_{r, w c} \quad$ Radiation heat transfer from windshield to car cabin (W)

$T \quad$ Air temperature within car cabin $\left({ }^{\circ} \mathrm{C}\right)$

$T_{a} \quad$ Ambient temperature $\left({ }^{\circ} \mathrm{C}\right)$

$T_{e, c} \quad$ Temperature of cover in envelope $\left({ }^{\circ} \mathrm{C}\right)$

$T_{e, i} \quad$ Temperature of insulator in envelope $\left({ }^{\circ} \mathrm{C}\right)$

$T_{e, s} \quad$ Temperature of steel in envelope $\left({ }^{\circ} \mathrm{C}\right)$

$T_{f, i} \quad$ Temperature of insulator in floor $\left({ }^{\circ} \mathrm{C}\right)$

$T_{f, s} \quad$ Temperature of steel in floor $\left({ }^{\circ} \mathrm{C}\right)$

$T_{s} \quad$ Temperature of supply air $\left({ }^{\circ} \mathrm{C}\right)$ $r_{g} \quad$ Reflectivity of ground

$u \quad$ Vector containing of weights and biases

$v \quad$ Wind speed $(\mathrm{m} / \mathrm{s})$

w Absolute humidity within cabin air $(\mathrm{kg} / \mathrm{kg})$

$w_{a} \quad$ Ambient absolute humidity (kg/kg)

$w_{j} \quad$ Weight from hidden-layer variable $j$

to output variable

Weight from input variable $i$

$w_{j i} \quad$ to hidden layer variable $j$

$w_{s} \quad$ Absolute humidity of supply air $(\mathrm{kg} / \mathrm{kg})$

$\alpha_{s} \quad$ Absorptivity of steel

$\alpha_{w} \quad$ Absorptivity of windshield

$\rho \quad$ Density of dry air $\left(\mathrm{kg} / \mathrm{m}^{3}\right)$

$\rho_{c} \quad$ Density of cover $\left(\mathrm{kg} / \mathrm{m}^{3}\right)$

$\rho_{i} \quad$ Density of insulator $\left(\mathrm{kg} / \mathrm{m}^{3}\right)$

$\rho_{s} \quad$ Density of steel $\left(\mathrm{kg} / \mathrm{m}^{3}\right)$

$\rho_{w} \quad$ Density of windshield $\left(\mathrm{kg} / \mathrm{m}^{3}\right)$

$\varepsilon_{c} \quad$ Emissivity of cover

$\varepsilon_{i} \quad$ Emissivity of insulator

$\varepsilon_{s} \quad$ Emissivity of steel

$\varepsilon_{w} \quad$ Emissivity of windshield

$\tau_{w} \quad$ Transmissivity of windshield

$\sigma \quad$ Stefan-Boltzman constant $\left(\mathrm{W} / \mathrm{m}^{2 \circ} \mathrm{C}^{4}\right)$

$\mu \quad$ Step size 


\section{Introduction}

Nowadays, climate control inside a car cabin is crucial to ensure comfort and safety for passengers during traveling under unpleasant outdoor-air conditions. In turn, automobile engineering designers have to describe all state variables of air conditions within a car cabin, which are in relation to thermal comfort, air quality, and energy usage. In principle, an air-conditioning system of a car is to maintain comfort conditions of clean air with efficient energy consumption. For example, a computerized system may automate an air conditioning unit or fans so as to keep cabin temperature and makeup air movement at a comfortable level all the time. Those requirements are challenging for research and development to precisely investigate dynamic behaviors of state variables, such as air temperature, relative humidity, and carbon dioxide concentration within a car cabin.

Up to now, most theoretical models, based on principle of energy and mass balances, have been developed to determine dynamics of the air temperature within a car cabin (Khayyam et al., 2009, 2011a, 2011b; Lee et al., 2015). Those mathematical models are intentionally applied to assess temperature control of an air-conditioning unit within a car cabin. Although various thermal loads from cabin components and environments are considered, the energy, which is carried by water vapor in air, is usually not taken into account. Recently, heat gains due to ventilation and human metabolism have been included for sensible heat and latent loads of moisture in (Fayazbakhsh and Bahrami, 2013). Those mathematical models were used to investigate energy consumption of an air-conditioning unit in reality. Simulated results of a lumped element model were greatly close to experimental results of temperature during warm-up and cool-down within a car cabin (Torregrosa-Jaime et al., 2015). Besides, there is a further attempt in regarding each compartment of a car envelope as a thermal mass (Marcos et al., 2014). The energy balances of compartments are presented to determine the temperature of each compartment in real time. Table 1 shows assorted thermal loads to the mathematical models in literature. It is noticed that there has been rare modeling of carbon dioxide concentration, which is an implicit indicator of air quality within a car cabin (Jung, 2013). Also, there has not been any study to include all thermal loads of a car cabin and carbon dioxide concentration in the mathematical models. Some parameters and physical properties are unknown or/and uncertain to be determined such as volume of cabin, area of car envelope, heat transfer coefficients, and thermal characteristics of materials. The approximation to those values from experiences may lead to inferior predictions for best practice at present.

Table 1 Thermal loads in previous models.

\begin{tabular}{|c|c|c|c|c|c|c|c|c|c|c|c|c|c|c|c|}
\hline Works & $\dot{m}_{w}$ & $M$ & $G_{\tau, w}$ & $G_{r, g}$ & $\dot{Q}_{C, w}$ & $\dot{Q}_{r, w}$ & $\dot{Q}_{c, e c}$ & $\dot{Q}_{r, e c}$ & $\dot{Q}_{C, f c}$ & $\dot{Q}_{r, f}$ & $W$ & $\dot{m}_{s}$ & $\dot{m}_{i n}$ & $\dot{m}_{r}$ & C \\
\hline $\begin{array}{c}\text { Khayyam, } \\
2009\end{array}$ & & $\mathrm{Y}$ & Y & Y & $\mathrm{Y}$ & & Y & & Y & & & $\mathrm{Y}$ & & $\mathrm{Y}$ & \\
\hline $\begin{array}{c}\text { Khayyam, } \\
\text { 2011a }\end{array}$ & & $\mathrm{Y}$ & Y & $\mathrm{Y}$ & $\mathrm{Y}$ & & Y & & Y & & & $\mathrm{Y}$ & & Y & $\mathrm{Y}$ \\
\hline $\begin{array}{c}\text { Khayyam, } \\
\text { 2011b }\end{array}$ & & $\mathrm{Y}$ & Y & $\mathrm{Y}$ & $\mathrm{Y}$ & & $\mathrm{Y}$ & & $\mathrm{Y}$ & & & $\mathrm{Y}$ & & $\mathrm{Y}$ & $\mathrm{Y}$ \\
\hline Lee, 2015 & & $\mathrm{Y}$ & Y & & $\mathrm{Y}$ & & Y & & Y & & & Y & & $\mathrm{Y}$ & \\
\hline $\begin{array}{c}\text { Fayazbakhsh, } \\
2013\end{array}$ & $\mathrm{Y}$ & $\mathrm{Y}$ & Y & Y & $\mathrm{Y}$ & & $\mathrm{Y}$ & & $\mathrm{Y}$ & & & $\mathrm{Y}$ & & $\mathrm{Y}$ & \\
\hline $\begin{array}{l}\text { Torregrosa- } \\
\text { Jaime, } 2015\end{array}$ & Y & $\mathrm{Y}$ & $\mathrm{Y}$ & & $\mathrm{Y}$ & Y & $\mathrm{Y}$ & Y & $\mathrm{Y}$ & $\mathrm{Y}$ & $\mathrm{Y}$ & Y & & Y & \\
\hline $\begin{array}{c}\text { Marcos, } \\
2014\end{array}$ & & $\mathrm{Y}$ & Y & & $\mathrm{Y}$ & Y & Y & $\mathrm{Y}$ & Y & $\mathrm{Y}$ & & & & & \\
\hline
\end{tabular}

Remark: Y means the thermal load is taken in account.

To overcome such problems, bilateral analyses between artificial neural networks and theoretical models for effective 
dynamic prediction of air conditions within car cabin are proposed in this work. Theoretical models with all thermal loads in Table 1 are applied to determine state variables: air temperature, and humidity, particularly including carbon dioxide concentration. The theoretical models are used to gain knowledge of air conditions so as to not only formulate understandable input/output relations but also generate training data for artificial neural networks since most conditions can be simulated easily to make sure artificial neural networks learns all possible conditions without experimental efforts. Hence, artificial neural networks are implemented as universal models in mathematical modeling (Atthajariyakul and Leephakpreeda, 2005; Ng et al., 2014; Von Grabe, 2016) when knowledge of input/output relations of artificial neural networks are acquired from the theoretical models regardless of knowing parameters and physical properties. A few experiments in driving/or parking conditions are used for refined training to obtain greatly acceptable prediction under various changes of thermal loads from actual environments.

\section{Experimental setup}

In Fig. 1(a), the experiments of a sedan car under parking, idling and driving conditions are performed for model validation of the proposed methodology. In outdoor parking, measurements are implemented from 9.00 am to 4.30 pm to observe overheating situation within a car cabin from sunlight, in time. On the other hand, an air-conditioning unit is turned on for maintaining comfort zone under idling and driving conditions, as usual. Fan and ventilation apertures are intentionally adjusted by a driver and passengers to yield various make-up air conditions. Figure 1(b) shows installation of measurement devices and data acquisition system in a car cabin where the letters are positioned by $\mathrm{T}$ for temperature, $\mathrm{R}$ for relative humidity, $\mathrm{C}$ for concentration of carbon dioxide, $\mathrm{v}$ for wind speed, and $\mathrm{G}$ for solar irradiation. The sensors to observe air conditions within a car cabin are located at the center of chamber around a chest level. The supply-air velocity of air-conditioning unit is measured for calculation of a mass flow rate passing through areas of grilles. The sensors of solar irradiation and wind speed are located on the roof of the car, while ambient temperature is measured outside at the same level of a car cabin.

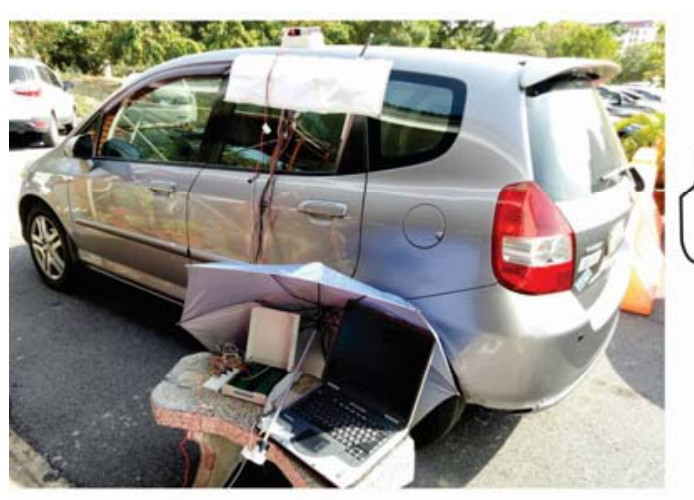

(a)

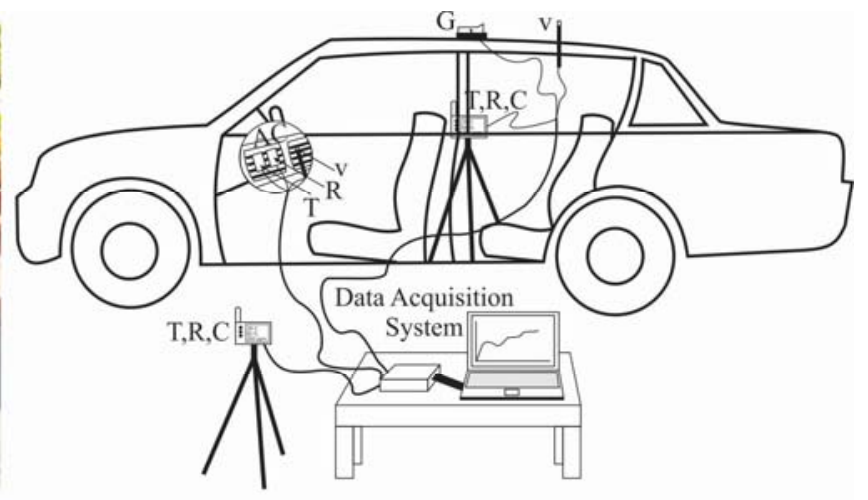

(b)

Fig. 1 Installation of measurement devices at car cabin: (a) sedan car and (b) schematic diagram

In each scenario, all data from measurement devices are transmitted and recorded every second by data acquisition card MCC DAS16/16AO ${ }^{\mathrm{TM}}$. The air temperature within a car cabin is measured by using a type-K thermocouple converter ShinkoDCL-33A-A/M ${ }^{\mathrm{TM}}$ with range from $0{ }^{\circ} \mathrm{C}$ to $100^{\circ} \mathrm{C}$ and an accuracy of $\pm 0.3^{\circ} \mathrm{C}$. With RotronicCF1 ${ }^{\mathrm{TM}}$, the relative humidity is measured in a measurement range 10 to $90 \% \mathrm{RH}$ with an accuracy of $<3 \% \mathrm{RH}$ while the carbon dioxide concentration is measured with range 0 to $5,000 \mathrm{ppm}$ with an accuracy of $\pm 40 \mathrm{ppm}$. Air velocity transmitter RotronicAF $1^{\mathrm{TM}}$, with range 0 to $20 \mathrm{~m} / \mathrm{s}$ and accuracy of $\pm 3 \% \mathrm{FS}$, is used to measure the wind speed. A pyranometer SolData98 $\mathrm{HP}^{\mathrm{TM}}$ is used to measure solar radiation in a range of $0-1,999 \mathrm{~W} / \mathrm{m}^{2}$ with accuracy of $\pm 5 \% \mathrm{FS}$.

\section{Methodology}

\subsection{Theoretical modeling approach}

In this section, lumped element models of a car cabin are developed to describe dynamic behaviors of air and carbon dioxide. Those conditions within a car cabin are defined from state variables: temperature of air, humidity, and carbon 
dioxide concentration. Particularly, they are applied to quantify significant factors in automotive engineering design such as thermal comfort of passengers, air quality within a car cabin, and energy consumption of a car (Mezrhab and Bouzidi, 2006;Leephakpreeda et al., 2001). In theoretical modeling, principles of mass and energy balance are taken in account. According to Eq. (1), the total irradiation from sunlight interacts with a glass plate of windshield where a radiation balance consists of reflection, absorption, and transmission processes (Incropera, 2002), as shown Fig. 2(a).

$$
G=G_{r}+G_{\alpha}+G_{\tau}
$$

Fig. 2(b) shows a control volume of the windshield. Unlike reflection and transmission, the radiative absorption has an effect of increasing the internal energy of glass windshield. Eq. (2) indicates that the internal energy of the windshield is governed by not only the absorbed radiation but also convection and radiation heat transfers to surroundings/car cabin. The energy equation of windshield is written as:

$V_{w} \rho_{w} c_{w} \frac{d T_{w}}{d t}=\underbrace{\alpha_{w} A_{w} G}_{G_{\alpha, w}}-[\underbrace{h A_{w}\left(T_{w}-T_{a}\right)}_{\dot{Q}_{c, w a}}+\underbrace{\varepsilon_{w} \sigma A_{w}\left(T_{w}^{4}-T_{a}^{4}\right)}_{\dot{Q}_{r, w a}}+\underbrace{h A_{w}\left(T_{w}-T\right)}_{\dot{Q}_{c, w c}}+\underbrace{\varepsilon_{w} \sigma A_{w}\left(T_{w}^{4}-T^{4}\right)}_{\dot{Q}_{r, w c}}]$

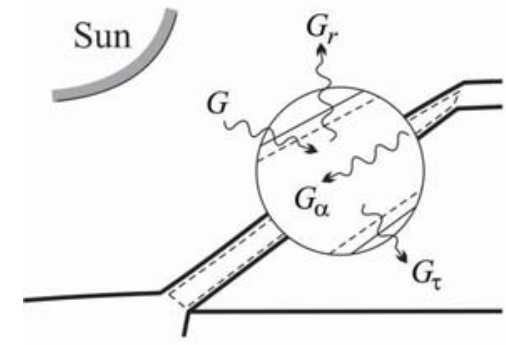

(a)

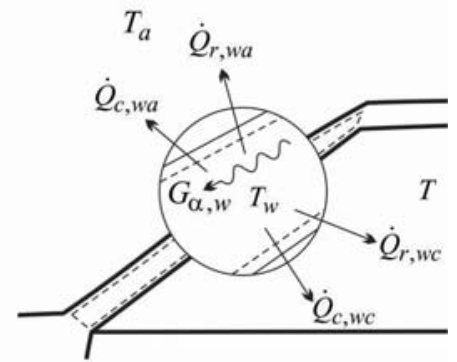

(b)

Fig. 2 Schematic diagram of windshield: (a) irradiance and (b) energy balance

Apart from transparent wind shield, opaque envelopes, such as roof, car body and floor, also absorb solar radiation in the process of radiative heating where the temperature of air within car cabin increase with dynamic balance of heat transfer to surrounding as illustrated in Fig 3.

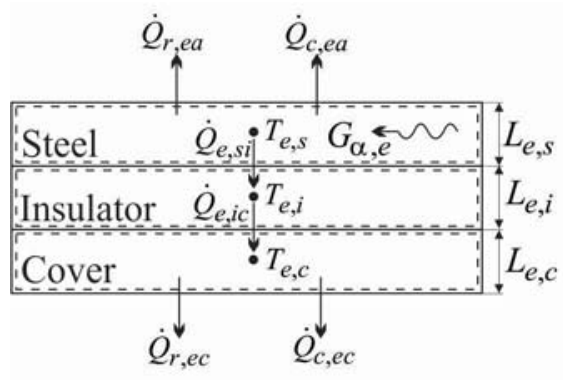

(a)

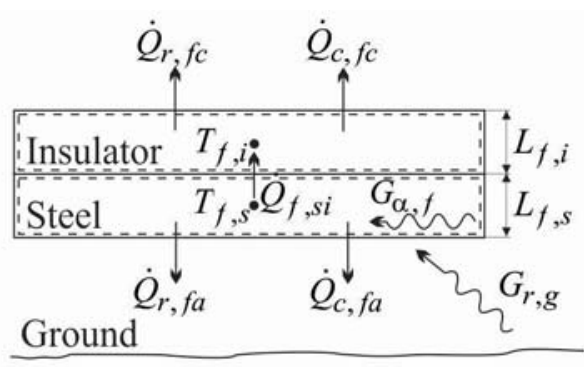

(b)

Fig. 3 Schematic diagram of energy balance for: (a) envelope and (b) floor

The envelopes are cooled through the conduction heat transfer, which takes place at each contact area between two plates of different materials. The thermal relations within envelopes and car floor are governed by:

at steel in envelope

$V_{e, s} \rho_{s} c_{s} \frac{d T_{e, s}}{d t}=\underbrace{\alpha_{e, s} A_{e} G}_{G_{a, e}}-[\underbrace{h A_{e}\left(T_{e, s}-T_{a}\right)}_{\dot{Q}_{c, e a}}+\underbrace{\varepsilon_{s} \sigma A_{e}\left(T_{e, s}^{4}-T_{a}^{4}\right)}_{\dot{Q}_{r, e a}}+\underbrace{\left(\frac{k_{e, s} A_{e}}{0.5 L_{e, s}}+\frac{k_{e, i} A_{e}}{0.5 L_{e, i}}\right)\left(T_{e, s}-T_{e, i}\right)}_{\dot{Q}_{e, s i}}]$

at insulator in envelope 
$V_{e, i} \rho_{i} c_{i} \frac{d T_{e, i}}{d t}=\underbrace{\left(\frac{k_{e, s} A_{e}}{0.5 L_{e, s}}+\frac{k_{e, i} A_{e}}{0.5 L_{e, i}}\right)\left(T_{e, s}-T_{e, i}\right)}_{Q_{e, s i}}-\underbrace{\left(\frac{k_{e, i} A_{e}}{0.5 L_{e, i}}+\frac{k_{e, c} A_{e}}{0.5 L_{e, c}}\right)\left(T_{e, i}-T_{e, c}\right)}_{Q_{e, i c}}$

at cover in envelope

$$
V_{e, c} \rho_{c} c_{c} \frac{d T_{e, c}}{d t}=\underbrace{\left(\frac{k_{e, i} A_{e}}{0.5 L_{e, i}}+\frac{k_{e, c} A_{e}}{0.5 L_{e, c}}\right)\left(T_{e, i}-T_{e, c}\right)}_{Q_{e, c}}-[\underbrace{h A_{e}\left(T_{e, c}-T\right)}_{\dot{Q}_{c, e c}}+\underbrace{\varepsilon_{c} \sigma A_{e}\left(T_{e, c}^{4}-T^{4}\right)}_{\dot{Q}_{r, e c}}]
$$

at steel in floor

$V_{f, s} \rho_{s} c_{s} \frac{d T_{f, s}}{d t}=\underbrace{\alpha_{s} A_{f} \overbrace{\left(r_{g} G\right)}^{G_{r, g}}}_{G_{\alpha, b}}-[\underbrace{h A_{f}\left(T_{f, s}-T_{a}\right)}_{\dot{Q}_{c, f a}}+\underbrace{\varepsilon_{s} \sigma A_{f}\left(T_{f, s}^{4}-T_{a}^{4}\right)}_{\dot{Q}_{r, f a}}+\underbrace{\left(\frac{k_{f, s} A_{f}}{0.5 L_{f, s}}+\frac{k_{f, i} A_{f}}{0.5 L_{f, i}}\right)\left(T_{f, s}-T_{f, i}\right)}_{\dot{Q}_{f, s i}}]$

at insulator in floor

$$
V_{f, i} \rho_{i} c_{i} \frac{d T_{f, i}}{d t}=\underbrace{\left(\frac{k_{f, s} A_{f}}{0.5 L_{f, s}}+\frac{k_{f, i} A_{f}}{0.5 L_{f, i}}\right)\left(T_{f, s}-T_{f, i}\right)}_{Q_{b, s i}}-[\underbrace{h A_{f}\left(T_{f, i}-T\right)}_{\dot{Q}_{c, f c}}+\underbrace{\varepsilon_{i} \sigma A_{f}\left(T_{f, i}^{4}-T^{4}\right)}_{\dot{Q}_{r, f c}}]
$$

As illustrated in Fig. 4, the rate of change in internal energy of air is caused by the net energy gain and loss due to making up air, infiltration, exfiltration, heat transfer, and heat generation within a car cabin. The energy balance equation of moist air within car cabin is written as:

$$
V \rho\left(c+w c_{v}\right) \frac{d T}{d t}=\dot{E}_{i}-\dot{E}_{o}+\dot{Q}_{c, e c}+\dot{Q}_{r, e c}+\dot{Q}_{c, f_{c}}+\dot{Q}_{r, f c}+\dot{Q}_{c, w c}+\dot{Q}_{r, w c}+\tau_{w} G+N \dot{M}+W
$$

The energy, with which the supply air of an air-conditioning unit and the ambient air enter the car cabin, is determined, respectively, as:

$$
\dot{E}_{i}=\dot{m}_{s}\left(c+w_{s} c_{v}\right) T_{s}+\dot{m}_{i n}\left(c+w_{a} c_{v}\right) T_{a}
$$

On the other hand, the energy terms, with which the return air and the air leave the car cabin, is determined, respectively, as:

$$
\dot{E}_{O}=\dot{m}_{r}\left(c+w c_{v}\right) T+\dot{m}_{e X}\left(c+w c_{v}\right) T
$$

The supply air is regulated by mixing fresh air from surrounding and return air from car cabin. It is expressed as: $\dot{m}_{s}=\dot{m}_{f}+\dot{m}_{r}$

The mass balance equation of water vapor within the car cabin is written as:

$V \rho \frac{d w}{d t}=\dot{m}_{i n} w_{a}+\dot{m}_{s} w_{s}-\dot{m}_{e x} w-\dot{m}_{r} w+N \dot{H}$

Similarly, the mass balance equation of $\mathrm{CO} 2$ within the car cabin is written as:

$V \rho \frac{d C}{d t}=\dot{m}_{i n} C_{a}+\dot{m}_{f} C_{a}-\dot{m}_{e X} C-\underbrace{\left(\dot{m}_{s}-\dot{m}_{r}\right)}_{\dot{m}_{f}} C+N \dot{K}$

Eqs. (1)-(13) are simultaneously solved to determine state variables of air conditions such the temperatures, absolute humidity, and concentration of carbon dioxide within a car cabin under various surrounding conditions and number of passengers. Actually, physical properties are to be well predetermined for the finest prediction of the mathematical models. However, some values, such as volume of car cabin, area of body steel, and thermal properties, are difficult to be determined from measurement. Due to those uncertainties, there are deviations of simulated results from the observed values of state variables. To obtain the most acceptable solutions, an artificial neural network is proposed to refine the results of theoretical models close to observation data under real conditions, which is presented in next section. 


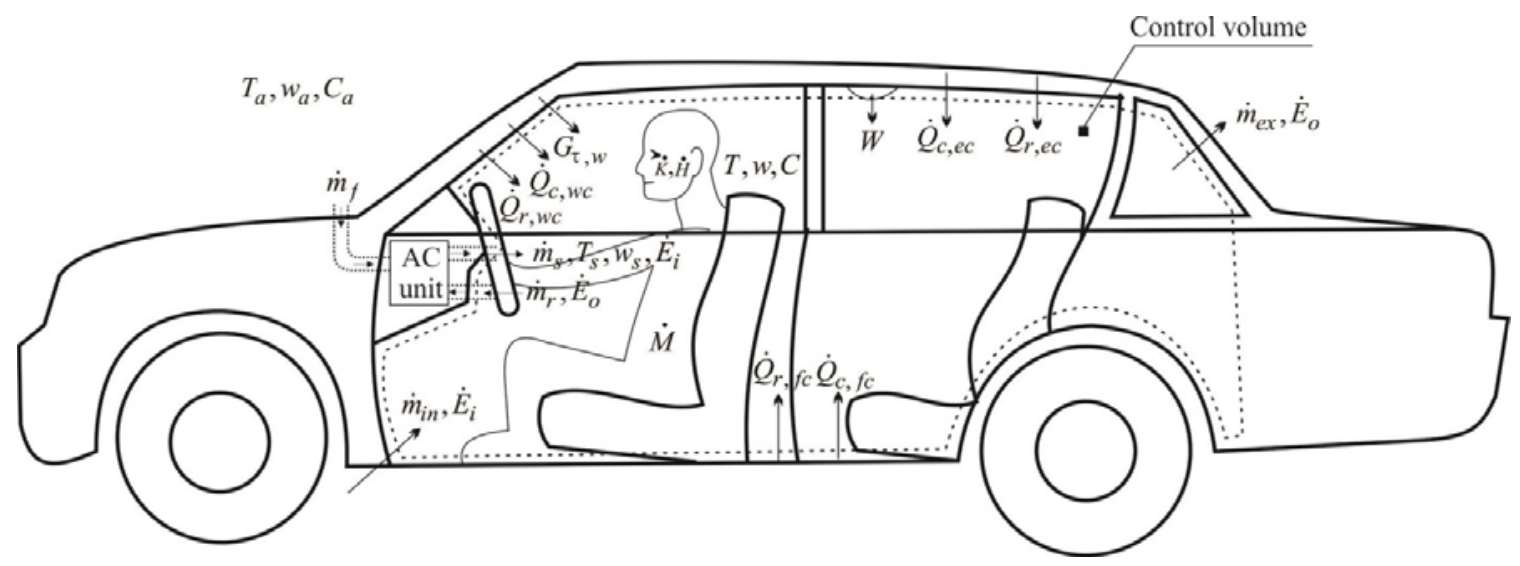

Fig. 4 Schematic diagram of energy and mass balances across control volume of car cabin

\subsection{Artificial neural network approach}

In this section, an artificial neural network is developed as a mathematical model in order to predict state variables of air within a car cabin close to observation data under various surrounding conditions. To understand the proposed scheme, the mathematical models from Eq. (2) to Eq. (13) are presented in flowchart of input/output functions since an artificial neural network is applied as a universal approximation function in mathematical modeling. The schematic structure is shown in Fig 5.

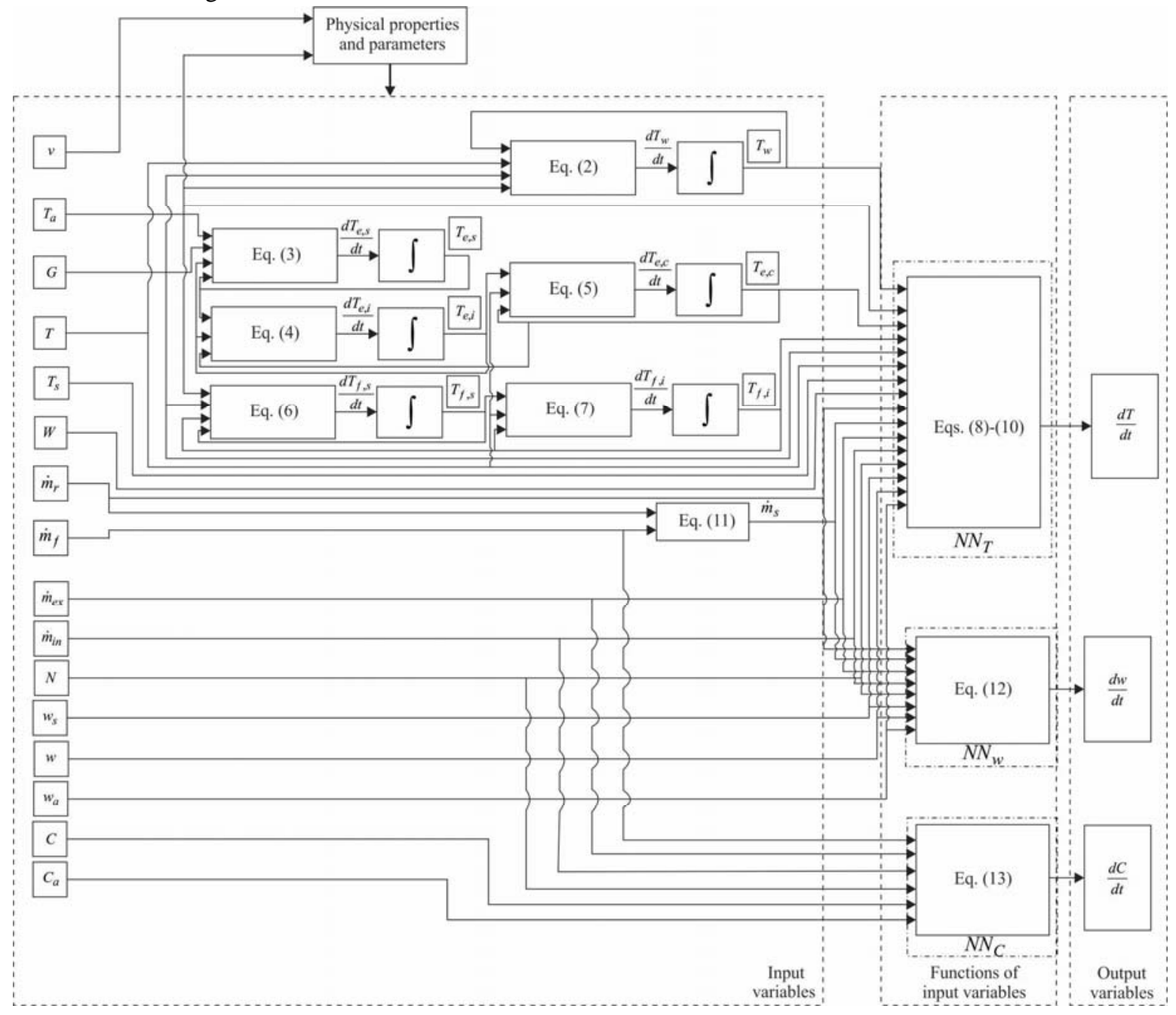

Fig. 5 Flowchart of function approximation by using artificial neural networks 
There are three sectors of input variables, functions of input variables, and output variables. The functions of input variables are to be replaced by artificial neural networks. The output variables are the derivatives of temperature, absolute humidity, and carbon dioxide concentration within a car cabin. Those functional derivatives are proposed without adding numbers of time-delayed inputs to input-output relations due to requirements in characterizing memory effects of dynamic behaviors. They are used to solve for the temperature, absolute humidity, and concentration of carbon dioxide in time. The artificial neural networks are expressed in terms of input variables as:

$$
\begin{aligned}
\frac{d T}{d t} & =f_{N N_{T}}\left(T, T_{s}, T_{w}, T_{e, c}, T_{f, i}, T_{a}, G, w, w_{s}, w_{a}, W, \dot{m}_{s}, \dot{m}_{r}, \dot{m}_{i n}, \dot{m}_{e x}, N\right) \\
\frac{d w}{d t} & =f_{N N_{W}}\left(w_{s}, w, w_{a}, \dot{m}_{s}, \dot{m}_{r}, \dot{m}_{i n}, \dot{m}_{e x}, N\right) \\
\frac{d C}{d t} & =f_{N N_{C}}\left(C_{a}, C, \dot{m}_{f}, \dot{m}_{i n}, \dot{m}_{e x}, N\right)
\end{aligned}
$$

In this study, the feed forward neural networks of three layers, such as input layer, hidden layer, and output layer, are applied to determine the state variables: temperature, absolute humidity, and concentration of carbon dioxide in the same way as Eqs. (14)-(16). It can be noticed that the derivatives of Eqs. (14)-(16) are functions of values of input variables at the present time. In turn, the temperature-dependent characteristics of properties are captured by the artificial neural networks in time from the change in temperature. From Fig. 6, the $N_{i} \times N_{j} \times 1$ artificial neural networks are written as the relationship between the output variable $O$ and input variables $I$, as expressed in Eqs. (17)-(18).

$$
\begin{aligned}
& O=f_{O}\left(\sum_{j=1}^{N_{j}} w_{j} H_{j}+b\right) \\
& H_{j}=f_{H}\left(\sum_{i=1}^{N_{i}} w_{j i} I_{i}+b_{j}\right)
\end{aligned}
$$

with the common activation functions $f_{O}(x)=x$ and $f_{H}(x)=1 /\left(1+e^{-x}\right)$.

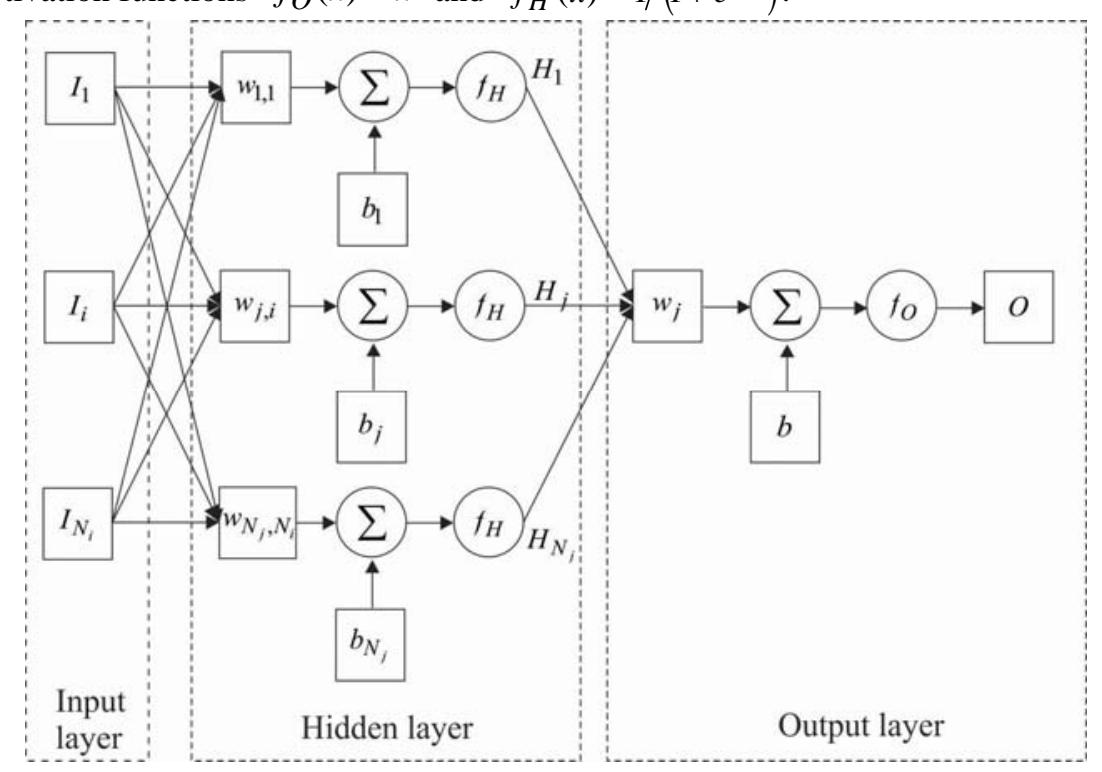

Fig. 6 Mathematical structure of feedforward neural network

For example, the number of input variables of artificial neural network in Eq. (14) is sixteen, that is $\left\{I_{1}, I_{2}, \cdots, I_{16}\right\}$ and the output variable of artificial neural network $O$ is $d T / d t$ The derivative functions of absolute humidity and concentration of carbon dioxide can be defined with the same consideration. In Eqs. (17)-(18), the weights and biases of artificial neural network are determined such as a way that the output variable of artificial neural networks mimics the desired output variable from observation. In turn, the number of desired output variables $O_{d}$ is needed in a training process. The performance index is defined as the mean squared error in Eq. (19). 


$$
\operatorname{MSE}(u)=\frac{\sum_{l=1}^{N_{t}}\left(O-O_{d}\right)_{l}^{2}}{N_{t}}
$$

Eq.(19) is minimized in the training process. The weights and biases are updated using Levenberg Marquardt method. This method is combination of Gauss-Newton algorithm and gradient descent algorithm. The weights and biases can be adjusted in the direction which the mean squared error in Eq. (19) decreases. The recursive algorithm to adjust the weights and biases is expressed as:

$$
u_{k+1}=u_{k}-\left(J_{k}^{T} J_{k}+\mu I_{m}\right)^{-1} J_{k}\left(O-O_{d}\right)_{k}
$$

The adjustment in training process is terminated when the mean squared error is sufficiently small. It should be remarked that the artificial neural networks can be applied to predict state variables of air within a car cabin much close to observation data by best fitting without knowledge of physical properties, unlike the theoretical models. However, the theoretical models are used to not only comprehensively give input/output structures for artificial neural networks but also meaningfully generate initial training data. After that, the experimental data is used to train artificial neural networks more precisely predict state variables under various surrounding conditions of a car cabin.

\section{Result and discussion}

In this section, bilateral analyses of artificial neural networks and theoretical models are applied to predict dynamic behaviors of air conditions within a sedan car under actual parking/driving environment. The car is parked and driven for real-time experiments where the air conditions within the car cabin are fully recorded. The data acquisition system, as mentioned in section 2, is implemented at a sampling rate of $1 \mathrm{~Hz}$. There are numbers of measurement data, which consist of air temperature, relative humidity of air, and carbon dioxide concentration within the car cabin, as well as temperature, relative humidity, and velocity of supply air at an outlet grille, relative outdoor-wind speed, ambient temperature, relative humidity, carbon dioxide concentration of surrounding, and solar irradiance.

Under parking condition, the car is parked in outdoor environment without a shadow of roof and cover. The experiment is performed from 9.00 am to $3.30 \mathrm{pm}$ on a day of November, 2016. It should be remarked that the air temperature is reported as a state variable under parking condition since there are no changes in the absolute humidity of air and concentration of carbon dioxide within the car cabin. It is found that the absolute humidity of air $w$ and concentration of carbon dioxide $C$ are measured at $0.0167 \mathrm{~kg} / \mathrm{kg}, 305 \mathrm{ppm}$, respectively. However, they vary under a driving condition and are presented in next case study. Exemplary plots of ambient temperature $T_{a}$, absolute humidity of outdoor air $w_{a}$, and wind speed $v$ against time, which are recorded during parking, are shown in Fig. 7(a)-7(c), respectively. In Fig. 7(d), the rate of radiation heat per unit area from sunlight is transferred through the car envelopes.

As depicted in Fig. 8(a), the theoretical models are numerically solved with those measured data, as input variables of Eqs. (2)-(11). The numerical values of parameters in Table 2 are determined to ensure best practice in numerical simulation. Without an air-conditioning unit in operation, other input variables of Eqs. (2)-(11) are defined as: $T_{s}=T$, $w_{s}=w, \dot{m}_{s}=0$, and $\dot{m}_{r}=0$ while there are not any infiltration $\dot{m}_{i n}=0$, exfiltration $\dot{m}_{e x}=0$, occupants within the car cabin $N=0$, and usage of electric appliances $W=0$. The simulated results of air temperature are presented with a solid line where the experimental data is comparatively plotted with a circle line. Due to radiation heat from sunlight, the air temperature within the car cabin increases according to balancing heat transfer between ambient environment and car cabin. From observation, the proposed models can be used to predict the air temperature within the car cabin. The coefficient of determination to perfect prediction line ( $100 \%$ accuracy), with $\mathrm{R}^{2}=0.7318$, indicates acceptable correlation of simulated results to experimental data, as illustrated in Fig. 8(b).

However, the simulated results are not fitted well to experimental data. Those deviations may be caused by uncertainty of parametric determination and/or the hypothesis of theoretical modeling. For example, the temperaturedependent parameters of theoretical models are approximately defined as constant values while temperatures of materials change. Also, it is assumed that there are three layers of car envelopes, which may not reflect actual structures in some locations of the car cabin where physical investigation is not allowed. 


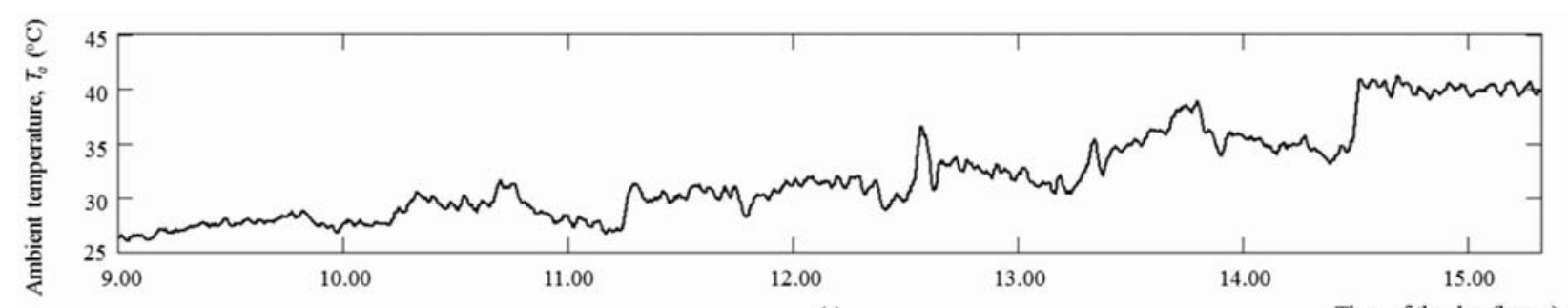

(a)

Time of the day (hours)

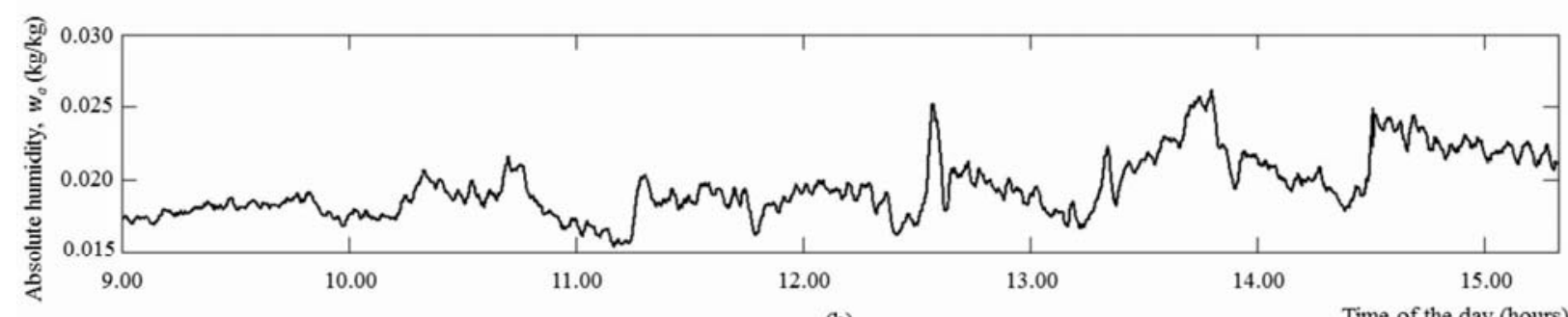

(b)

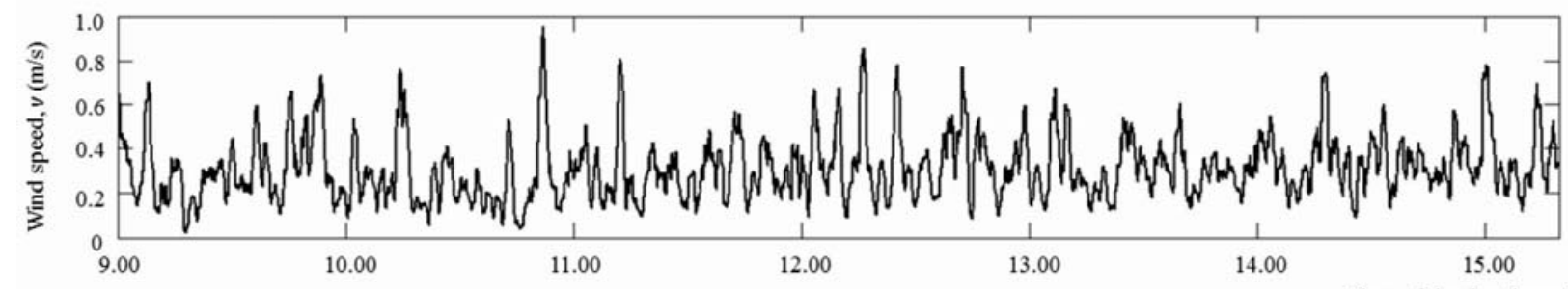

(c)

Time of the day (hours)

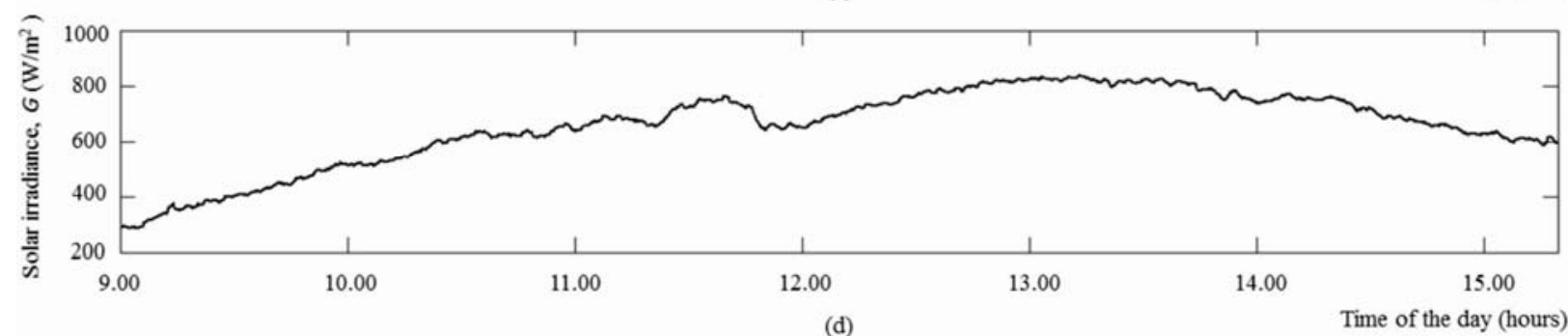

Fig. 7 Plots of measurement data during parking on a day in November, 2016: (a) ambient temperature, (b) absolute humidity of outdoor air, (c) wind speed, and (d) solar irradiance

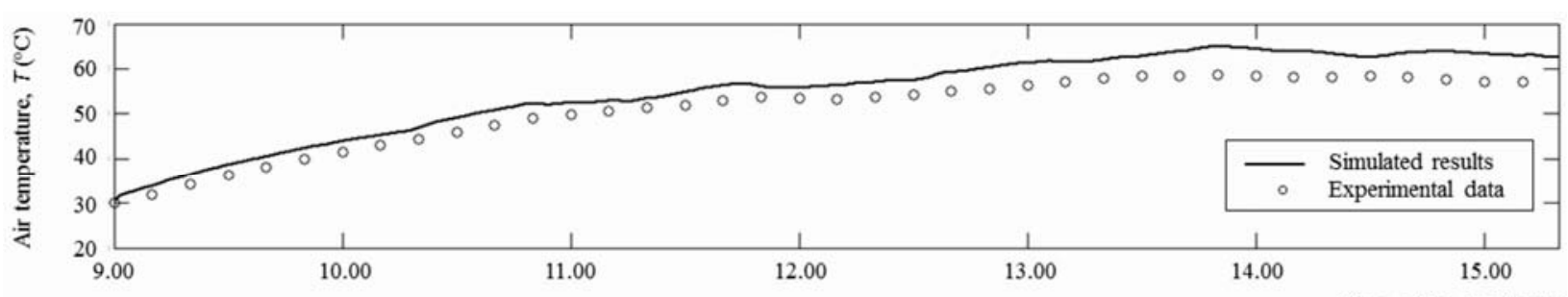

(a)

Time of the day (hours

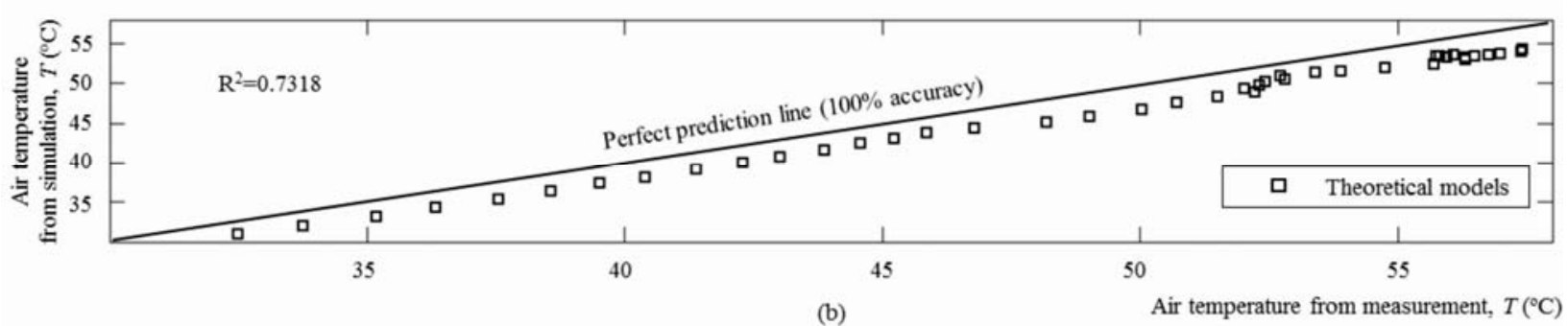

Fig. 8 Prediction performance of theoretical models compared with measurement data during parking: (a) time-series prediction and (b) analysis on correlation 
Kristanto and Leephakpreeda, Journal of Thermal Science and Technology, Vol.13, No.2 (2018)

Table 2 Numerical values of physical properties

\begin{tabular}{|c|c|c|c|}
\hline Property & Value & Property & Value \\
\hline$A_{e}$ & $7.3905 \mathrm{~m}^{2}$ & $k_{e, i}$ & $0.047 \mathrm{~W} / \mathrm{m}^{\circ} \mathrm{C}$ \\
\hline$A_{f}$ & $2.6816 \mathrm{~m}^{2}$ & $k_{e, s}$ & $60.5 \mathrm{~W} / \mathrm{m}^{\circ} \mathrm{C}$ \\
\hline$A_{w}$ & $0.2727 \mathrm{~m}^{2}$ & $k_{f, i}$ & $0.047 \mathrm{~W} / \mathrm{m}^{\circ} \mathrm{C}$ \\
\hline$H$ & $1.77 \times 10^{-5} \mathrm{~kg} / \mathrm{s}$ & $k_{f, s}$ & $60.5 \mathrm{~W} / \mathrm{m}^{\circ} \mathrm{C}$ \\
\hline$K$ & $7.37 \times 10^{-6} \mathrm{~kg} / \mathrm{s}$ & $r_{r}$ & 0.2 \\
\hline$L_{e, i}$ & $0.002 \mathrm{~m}$ & $\alpha_{s}$ & 0.35 \\
\hline$L_{e, s}$ & $0.004 \mathrm{~m}$ & $\alpha_{w}$ & 0.3 \\
\hline$L_{e, c}$ & $0.002 \mathrm{~m}$ & $\rho$ & $1.2 \mathrm{~kg} / \mathrm{m}^{3}$ \\
\hline$L_{f, i}$ & $0.002 \mathrm{~m}$ & $\rho_{c}$ & $750 \mathrm{~kg} / \mathrm{m}^{3}$ \\
\hline$L_{f, s}$ & $0.004 \mathrm{~m}$ & $\rho_{i}$ & $60 \mathrm{~kg} / \mathrm{m}^{3}$ \\
\hline$V_{w}$ & $0.0082 \mathrm{~m}^{3}$ & $\rho_{s}$ & $7900 \mathrm{~kg} / \mathrm{m}^{3}$ \\
\hline C & $1006 \mathrm{~J} / \mathrm{kg}^{\circ} \mathrm{C}$ & $\rho_{w}$ & $2590 \mathrm{~kg} / \mathrm{m}^{3}$ \\
\hline$C_{c}$ & $840 \mathrm{~J} / \mathrm{kg}^{\circ} \mathrm{C}$ & $\varepsilon_{s}$ & 0.98 \\
\hline$C_{i}$ & $1700 \mathrm{~J} / \mathrm{kg}^{\circ} \mathrm{C}$ & $\varepsilon_{w}$ & 0.88 \\
\hline$C_{s}$ & $450 \mathrm{~J} / \mathrm{kg}^{\circ} \mathrm{C}$ & $\varepsilon_{c}$ & 0.8 \\
\hline$C_{v}$ & $1840 \mathrm{~J} / \mathrm{kg}^{\circ} \mathrm{C}$ & $\varepsilon_{f}$ & 0.82 \\
\hline$c_{w}$ & $840 \mathrm{~J} / \mathrm{kg}^{\circ} \mathrm{C}$ & $\tau_{w}$ & 0.3 \\
\hline$h$ & $5.8+3.7 v \quad \mathrm{~W} / \mathrm{m}^{20} \mathrm{C}$ & $\sigma$ & $5.670 \times 10^{-8} \mathrm{~W} / \mathrm{m}^{2} \mathrm{~K}^{4}$ \\
\hline$k_{e, c}$ & $0.13 \mathrm{~W} / \mathrm{m}^{\circ} \mathrm{C}$ & & \\
\hline
\end{tabular}

To reduce differences between the simulated results and experimental data, artificial neural networks are applied to mimic exactly relations of input/output variables of air conditions within the car cabin. In the methodological flowchart of Fig. 5, the derivative function of air temperature in Eq. (14) is proposed to be captured by the artificial neural network. The numbers of input variables in Eq. (14) are sixteen where Eq. (14) is equivalent to Eqs. (8)-(11). In turn, the structures of 16x20x1 neurons of $N N_{T}$ are chosen from one of the best training outcomes. In other words, there are sixteen input variables, twenty neurons in a hidden layer, and a single output variable, which is the derivative of air temperature.

With bilateral analyses, there are two steps in preparation of training data. In the former, the desired output data is obtained from simulated results of derivative function from Eqs. (8)-(11) where it is straightforward to generate all feasible input variables without any experimental workloads. The numerical ranges of input variables are defined in Table 
3. Those values can be valid under any possible operating conditions. There are six hundred fifty-seven thousand and five hundred training data sets of simulated results from the theoretical models, which are used for training data.

Table 3 Numerical ranges of input variables

\begin{tabular}{|c|c|c|c|c|c|}
\hline Input variables & Range & Interval & Input variables & Range & Interval \\
\hline$T$ & 20 to $80^{\circ} \mathrm{C}$ & $20^{\circ} \mathrm{C}$ & $W$ & 0 to $100 \mathrm{~W}$ & $50 \mathrm{~W}$ \\
\hline$T_{s}$ & 10 to $20^{\circ} \mathrm{C}$ & $5^{\circ} \mathrm{C}$ & $\dot{m}_{s}$ & 0 to $0.12 \mathrm{~kg} / \mathrm{s}$ & $0.03 \mathrm{~kg} / \mathrm{s}$ \\
\hline$T_{w}$ & 20 to $80^{\circ} \mathrm{C}$ & $20^{\circ} \mathrm{C}$ & $\dot{m}_{r}$ & 0 to $0.12 \mathrm{~kg} / \mathrm{s}$ & $0.03 \mathrm{~kg} / \mathrm{s}$ \\
\hline$T_{e c}$ & 20 to $80^{\circ} \mathrm{C}$ & $20^{\circ} \mathrm{C}$ & $\dot{m}_{i n}$ & 0 to $0.03 \mathrm{~kg} / \mathrm{s}$ & $0.01 \mathrm{~kg} / \mathrm{s}$ \\
\hline$T_{f, i}$ & 20 to $80^{\circ} \mathrm{C}$ & $20^{\circ} \mathrm{C}$ & $\dot{m}_{e x}$ & 0 to $0.03 \mathrm{~kg} / \mathrm{s}$ & $0.01 \mathrm{~kg} / \mathrm{s}$ \\
\hline$T_{a}$ & 20 to $80^{\circ} \mathrm{C}$ & $20^{\circ} \mathrm{C}$ & $N$ & 0 to 3 persons & 1 person \\
\hline$G$ & 0 to $1200 \mathrm{~W} / \mathrm{m}^{2}$ & $300 \mathrm{~W} / \mathrm{m}^{2}$ & $\dot{m}_{f}$ & 0 to $0.12 \mathrm{~kg} / \mathrm{s}$ & $0.03 \mathrm{~kg} / \mathrm{s}$ \\
\hline$w$ & $\begin{array}{c}0.002 \text { to } 0.022 \\
\mathrm{~kg} / \mathrm{kg}\end{array}$ & $0.005 \mathrm{~kg} / \mathrm{kg}$ & $C$ & 250 to $3500 \mathrm{ppm}$ & $250 \mathrm{ppm}$ \\
\hline$w_{s}$ & $\begin{array}{l}0.02 \text { to } 0.035 \\
\mathrm{~kg} / \mathrm{kg}\end{array}$ & $0.005 \mathrm{~kg} / \mathrm{kg}$ & $C_{a}$ & 250 to $350 \mathrm{ppm}$ & $50 \mathrm{ppm}$ \\
\hline$w_{a}$ & $\begin{array}{c}0.002 \text { to } 0.022 \\
\mathrm{~kg} / \mathrm{kg}\end{array}$ & $0.005 \mathrm{~kg} / \mathrm{kg}$ & & & \\
\hline
\end{tabular}

In the latter, the desired output data is acquired from the experimental data where input variables vary according to actual parking condition. The desired output data $d T / d t$ is numerically determined by a ratio of measured value difference of air temperature to sampling time. For example, the output variable $d T / d t$ and sixteen input variables are summarized with Eq. (14). The feasible values of each input variable are generated according to specifications of range and interval in Table 3. The combinations of input variables are numerically simulated with Eq. (8) so as to yield corresponding output variables. This input-output data set is used to train the artificial neural network of Eq. (14) as training data from theoretical models. On the other hand, the input variables change in time during experiments and they are measured while the other input variables remain and they are set to be constants. The corresponding output variable $d T / d t$ is determined by the central difference of air temperature at each sampling time. This input-output data set is used to train the artificial neural network of Eq. (14) as training data from experiments.

The measured values of $v, G, T_{a}$, and $T$ from Fig.7 and Fig. 8(a) are used for input data of theoretical models in Eqs. (2)-(7). It can be noticed that air temperature within the car cabin changes approximately between $30{ }^{\circ} \mathrm{C}$ and 60 ${ }^{\circ} \mathrm{C}$ under parking condition since the air conditioning unit is not operated by a driver. The air within car cabin is heated with radiation of sunlight at those high temperatures. Accordingly, input variables of surface temperatures $T_{w}, T_{e, c}$, and $T_{f, i}$, which are inaccessible by measurement devices in practice, can be generated for training data. Like the theoretical models, other input variables are defined as: $T_{s}=T, w_{s}=w, \dot{m}_{s}=0, \dot{m}_{r}=0, \dot{m}_{i n}=0, \dot{m}_{e x}=0, N=0$, and $W=0$ under parking condition, while the input variable $w_{a}$ is defined from the measurement data in Fig. 7 . There are twenty-two thousand, seven hundred, and seventy training data sets of measurement data from experiment, which are used for training data. It can be noticed that the experiment itself cannot be performed to generate training data for the whole range of input variables. The numbers of input data from the experiment are $3.5 \%$ of the numbers of input data from the theoretical models.

Therefore, the input/output training data is combined with simulated results and experimental data. The weights and biases of the artificial neural network are adjusted by implementing the recursive formula in Eq. (20). It should be noted that the input/output variables are normalized in range of $[-1,1]$ for effortless convergence of weight/bias adjustment in 
this work. The weights and biases are obtained in Table A1 of appendix.

For model validation, the sedan car is parked on a day of March, 2017 from 9.00 am to 4.30 pm. As illustrated in Fig. 9, measurements of air conditions of the car cabin and environment are plotted against time. Fig. 10(a) shows timeseries predictions of air temperature within the car cabin, which are determined from the theoretical models with the parameters in Table 2 and artificial neural network with the weights and biases in Table A1. The predicted values from the artificial neural network track closer to the measured values of air temperature in time than the theoretical models. The coefficients of determination to perfect prediction are determined to be $\mathrm{R}^{2}=0.9394$ for the artificial neural network but $\mathrm{R}^{2}=0.7024$ for the theoretical models, as shown in Fig. 10(b).

The experiments under driving conditions take place on a day of May, 2017. The car engine and air conditioning unit are started for five minutes of idling and twenty-five minutes of driving at averaged speed of $25 \mathrm{~km} / \mathrm{hr}$. There are a driver and two observing passengers inside the car, that is $N=3$. The input variables of environment are measured and shown in Fig. 11 while other input variables of the air conditioning unit in the car are measured and illustrated in Fig. 12. The mass flow rates are estimated from measured velocity of supply air at $\dot{m}_{s}=0.09 \mathrm{~kg} / \mathrm{s}$, and $\dot{m}_{f}=0.081 \mathrm{~kg} / \mathrm{s}$. There are not any infiltration $\dot{m}_{i n}=0$, exfiltration $\dot{m}_{e x}=0$, and usage of electric appliance $W=0$.

Those input data from the experiment is used to generate training data of the artificial neural networks in Eq. (14), Eq. (15) and Eq. (16). After that, the artificial neural networks and theoretical models are applied to predict dynamic behaviors of moist air and carbon dioxide in another driving round. The simulated results of the air temperature, absolute humidity and carbon dioxide concentration are plotted against time, and compared to the measurement data with great agreement, as shown in Fig. 13(a), Fig. 13(c), and Fig. 13(e), respectively. Form Fig. 13(b), Fig. 13(d), and Fig. 13(f), it can be observed that the prediction on dynamic air conditions from the artificial neural networks with averaged $\mathrm{R}^{2}=0.9314$ is entirely closer to the perfect prediction line than the theoretical models with averaged $\mathrm{R}^{2}=0.7739$. The artificial neural network can perform the great prediction on the carbon dioxide concentration with $\mathrm{R}^{2}=0.9751$ since there are few numbers of input variables, physical properties, and parameters, which evolve the governing equation in Eq. (13).

In approach, it can be concluded that the artificial neural networks are trained by data of theoretical models for the cases such as parking and driving conditions. For example, the weighs and biases in Table A1 are obtained for prediction of air temperature. Subsequently, the artificial neural networks are further refined from training together with experimental data for accuracy of each condition.

\section{Conclusion}

The theoretical models, based on mass and energy balances, are applied to describe dynamic behaviors of air conditions within the car cabin in parking condition. The simulated results of air temperature track acceptably the measurement data in time on a day of November. However, the coefficient of determination to the perfect prediction, with $\mathrm{R}^{2}=0.7318$, indicates possibility of improvement on accuracy. Those differences may be caused by uncertainty of parametric determination and/or flaw hypothesis of modeling. To overcome such problems, artificial neural networks can be applied to mimic quantitative relations of input/output variables of air conditions without knowledge of the system. In this work, most training data are generated from theoretical models without experimental efforts whereas 3.5\% of total numbers of training data are obtained from experiment on the day of November. The artificial neural network is trained with the whole ranges of input variables from the theoretical models for close solutions and experimental data for refinement of prediction under different conditions. The data from theoretical models can be generated with much less effort, compared with data from experiments. It is found that the artificial neural network performs great prediction on air temperature within the car cabin on a day of March with $\mathrm{R}^{2}=0.9394$, which is much higher than the theoretical models with $\mathrm{R}^{2}=0.7024$ on the same day. In driving condition, the artificial neural networks are trained with the same bilateral analyses to predict air temperature, absolute humidity, and carbon dioxide concentration within the car cabin. The car is driven from idling to average running speed of $25 \mathrm{~km} / \mathrm{hr}$ in experiment. It is observed that the prediction from artificial neural networks is entirely closer to measurement data than theoretical models where the overall performances are justified by averaged $\mathrm{R}^{2}=0.9314$ for artificial neural networks and averaged $\mathrm{R}^{2}=0.7739$ for theoretical models. 


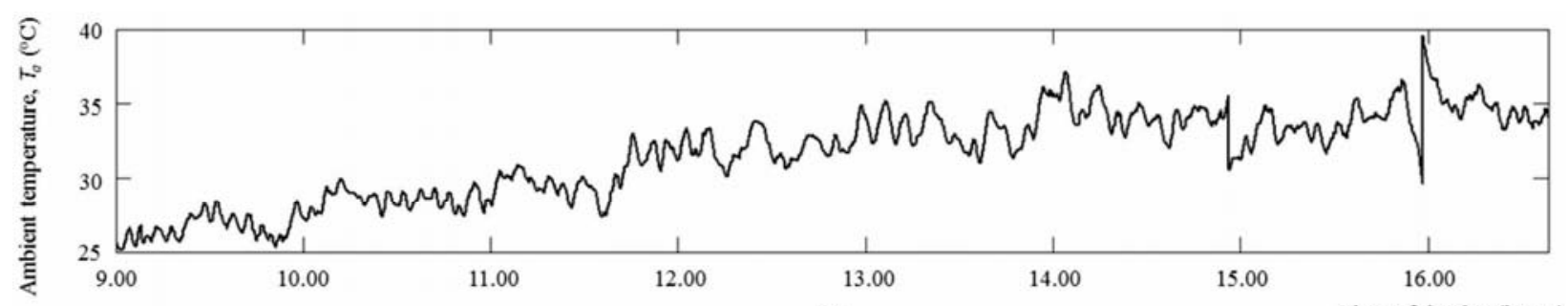

(a)

Time of the day (hours:
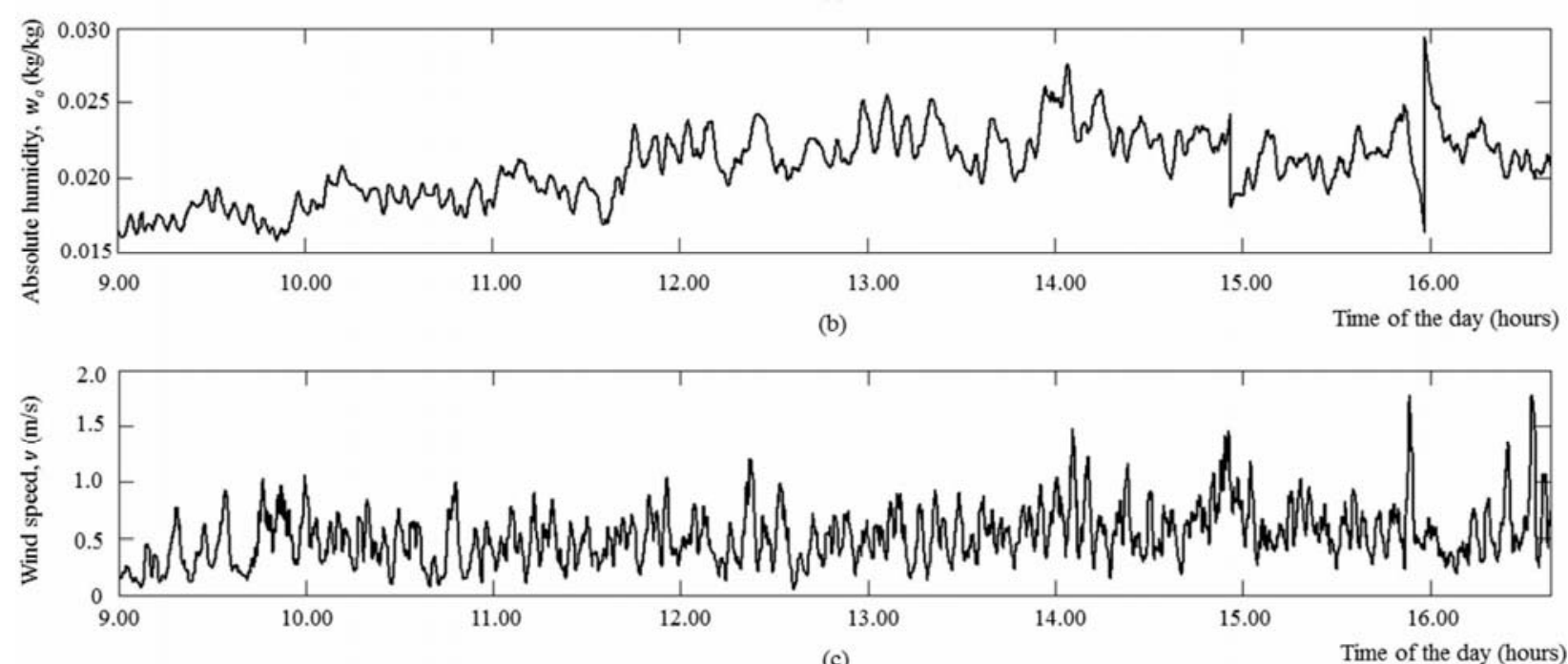

(c)

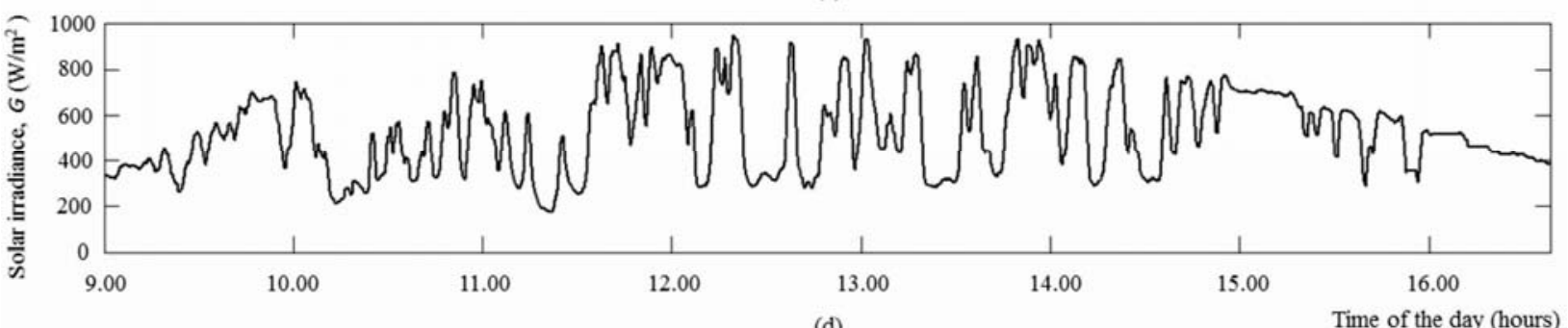

(d)

Time of the day (hours)

Fig. 9 Plots of measurement data during parking on a day in March, 2017: (a) ambient temperature, (b) absolute humidity of outdoor air, (c) wind speed, and (d) solar irradiance
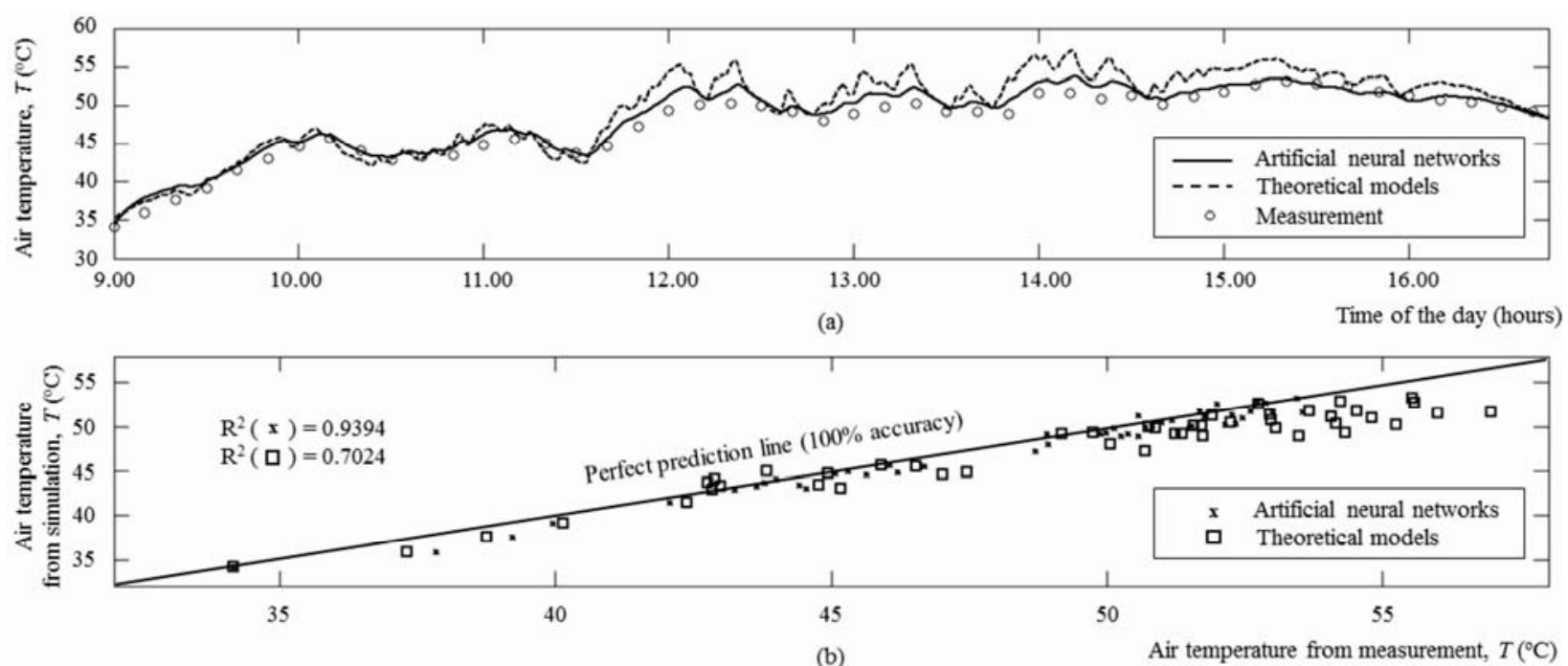

Fig. 10 Prediction performance of artificial neural network and theoretical models compared with measurement data during parking: (a) time-series predictions and (b) analysis on correlations 


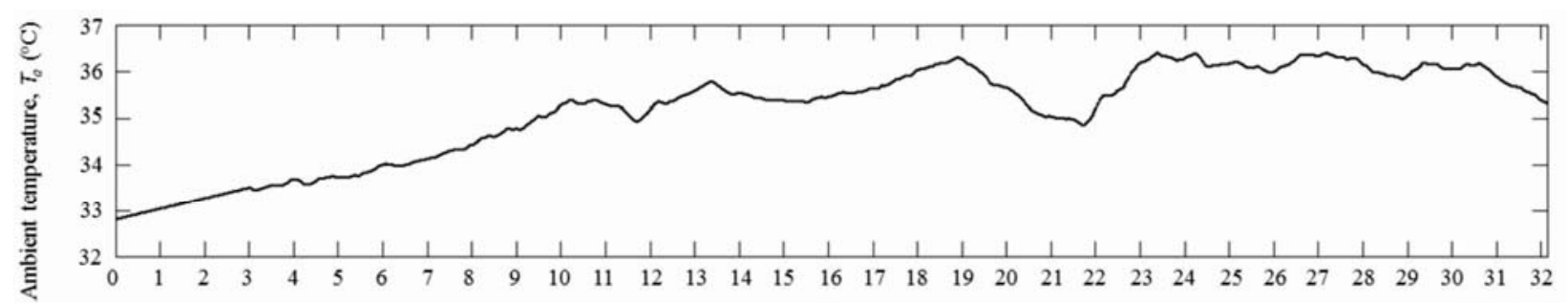

(a)

Time (min)

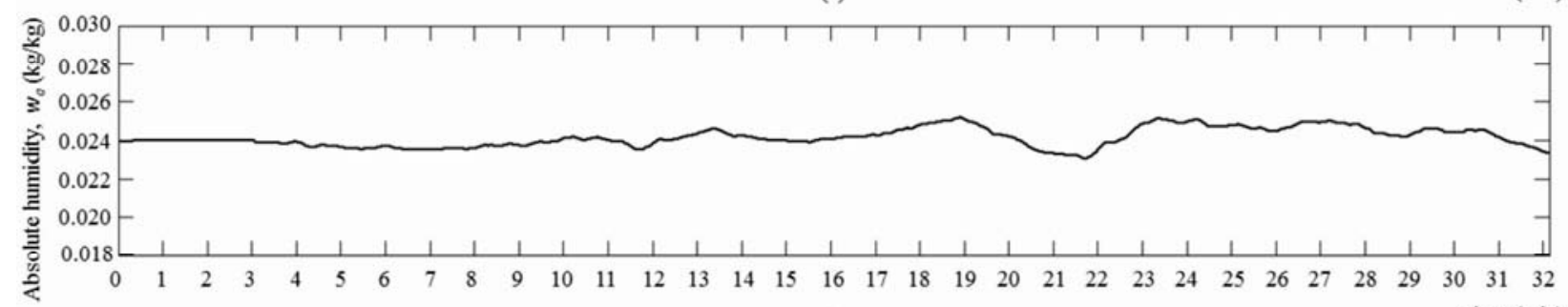

(b)

Time (min)

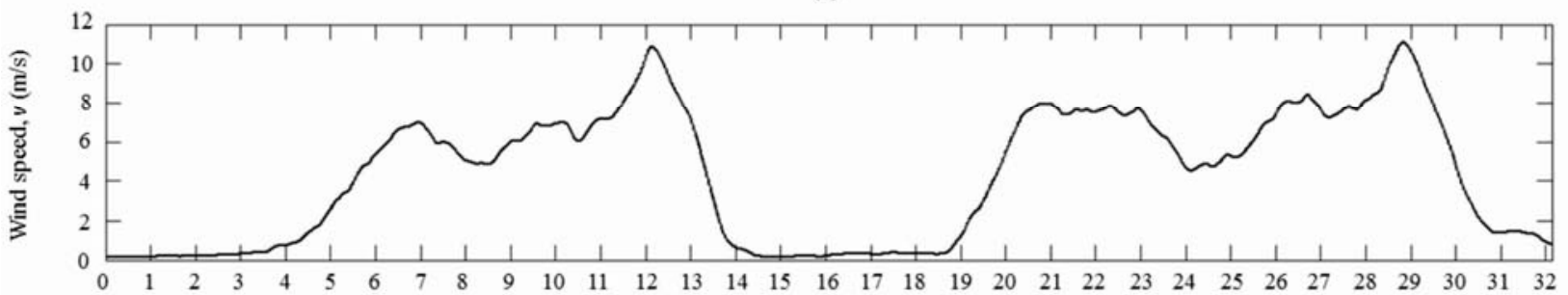

(c)

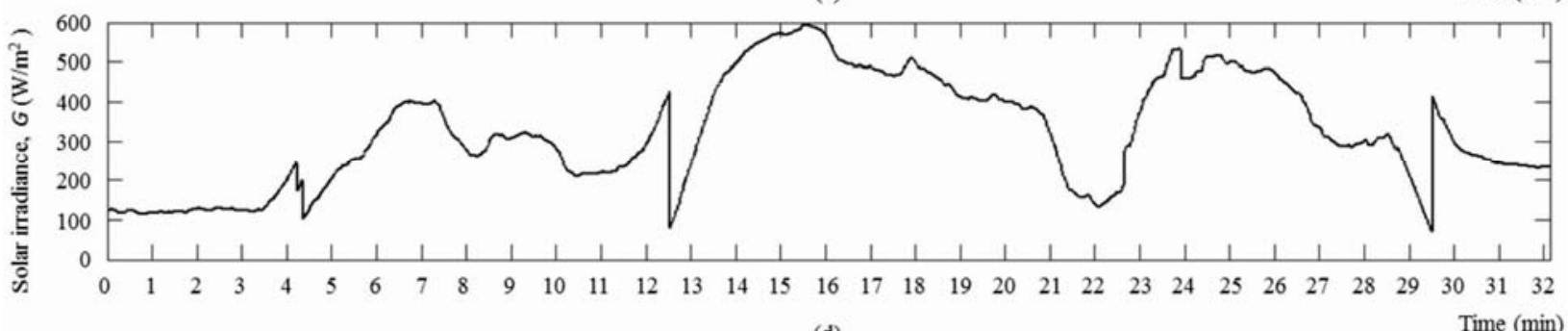

(d)

Fig. 11 Plots of measurement data during driving on a day in May, 2017: (a) ambient temperature, (b) absolute humidity of outdoor air, (c) wind speed, and (d) solar irradiance

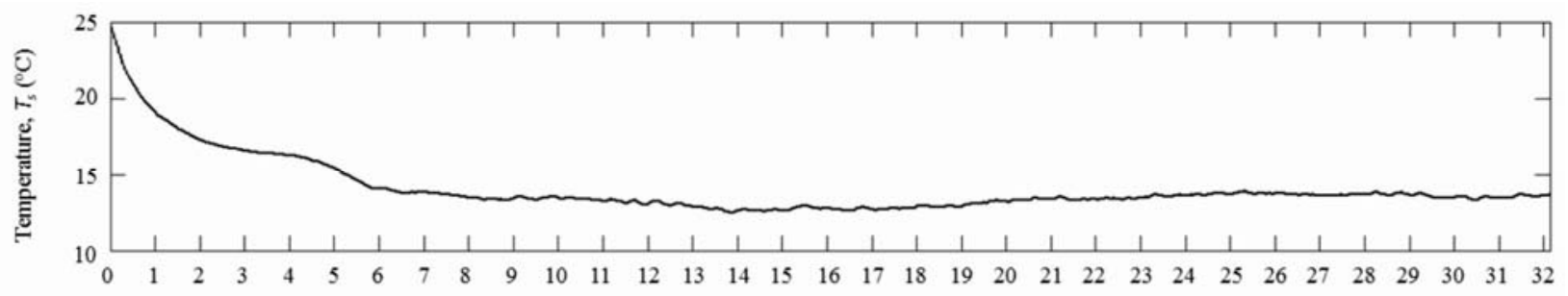

(a)

Time (min)

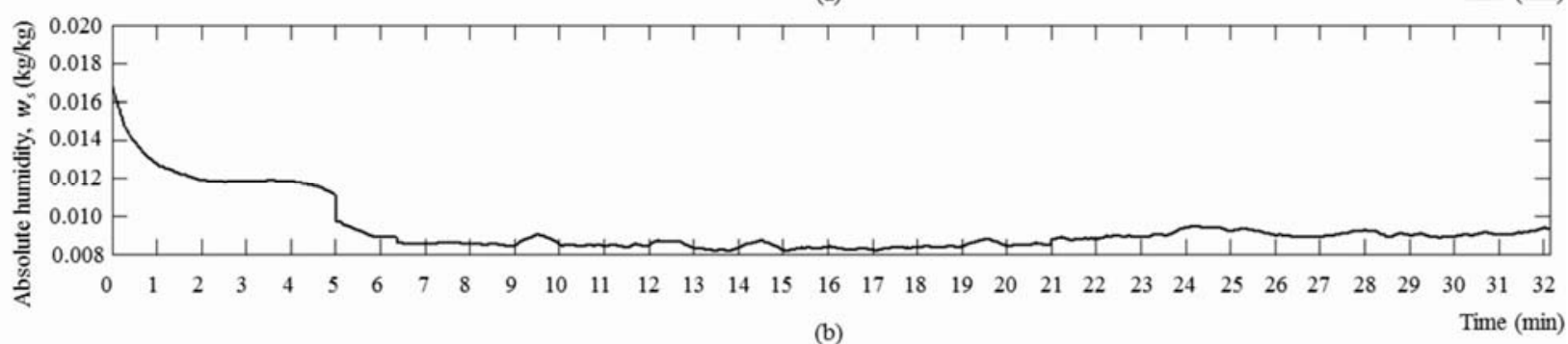

Fig. 12 Plots of measurement data during driving on a day in May, 2017: (a) supply-air temperature, and (b) absolute humidity of supply air 

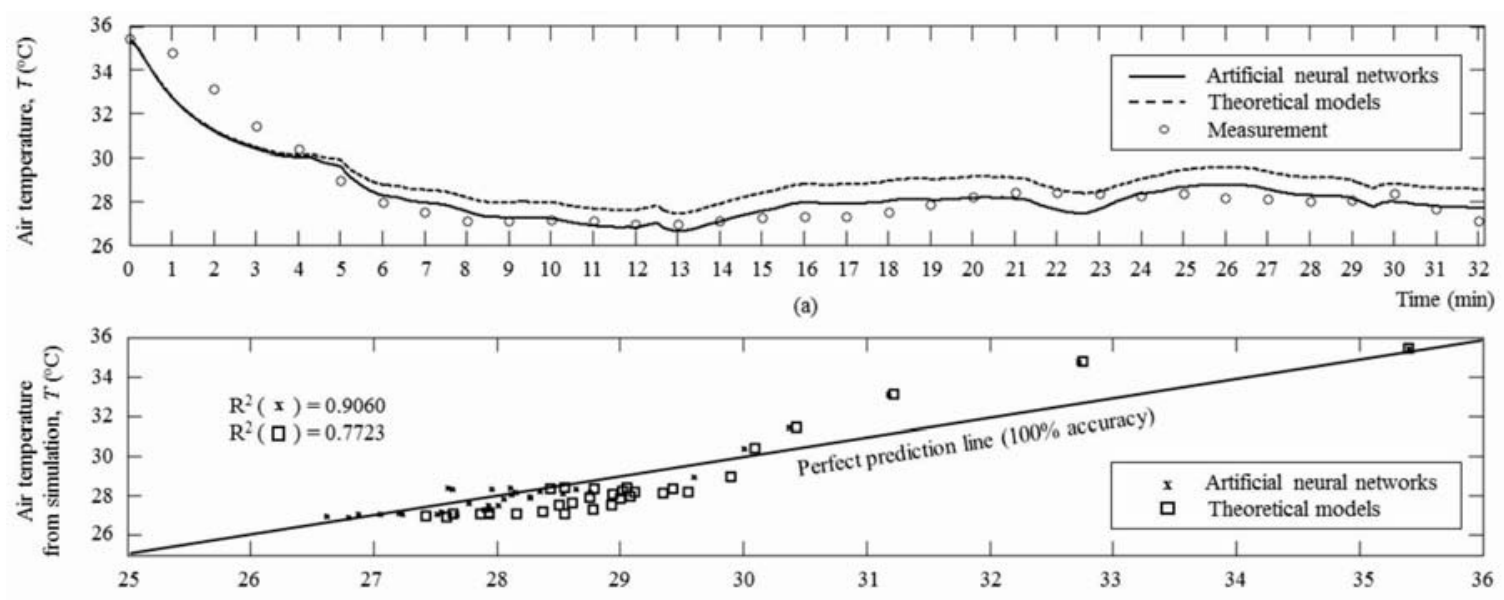

(b)

Air temperature from measurement, $T\left({ }^{\circ} \mathrm{C}\right)$
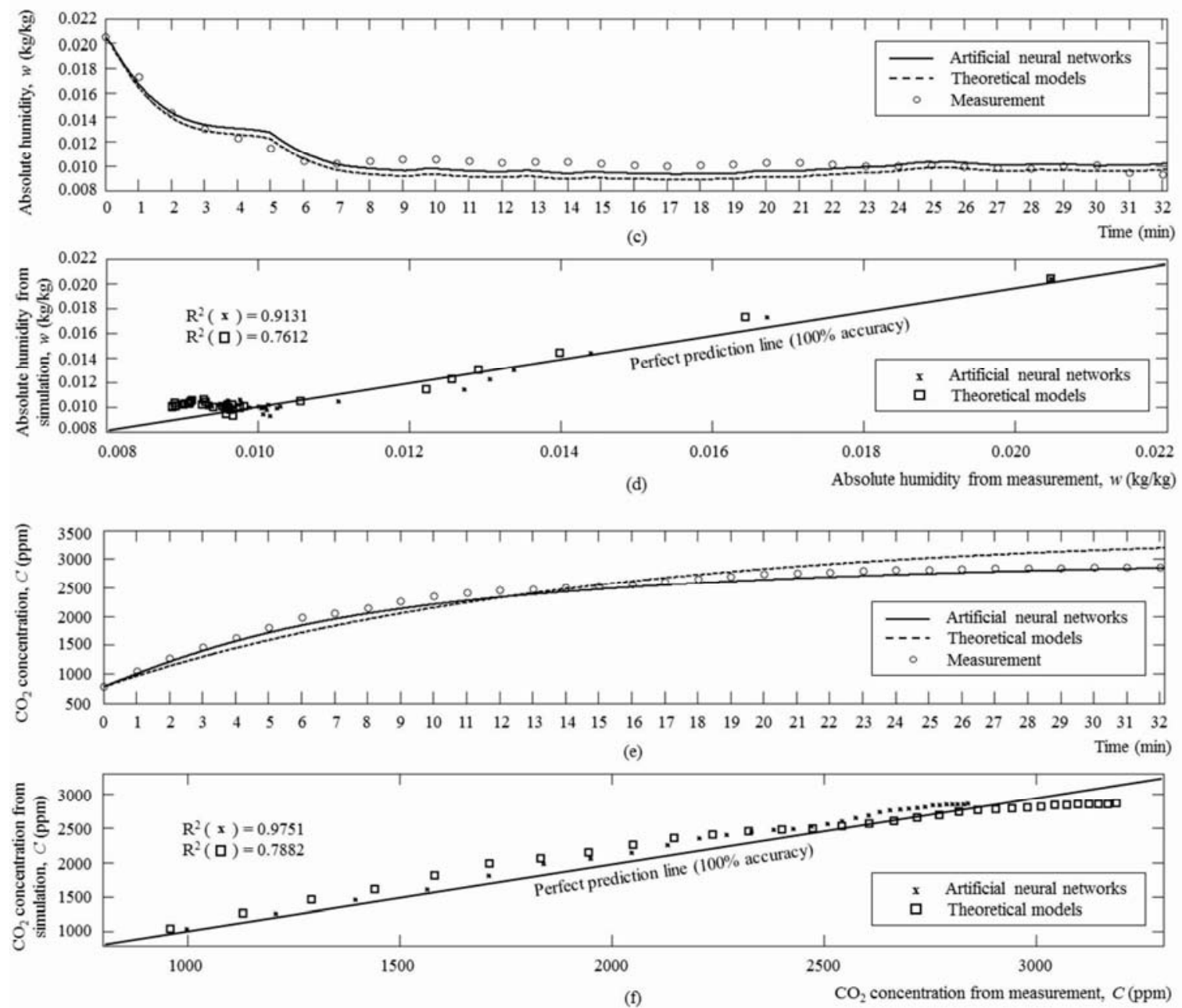

Fig. 13 Prediction performance of artificial neural networks and theoretical models compared with measurement data during driving: (a) time-series predictions on air temperature, (b) analysis on correlations of air temperature, (c) time-series predictions on absolute humidity of air, (d) analysis on correlations of absolute humidity of air, (e) time-series predictions on carbon dioxide concentration, and (f) analysis on correlations of carbon dioxide concentration 


\section{References}

Atthajariyakul, S., Leephakpreeda, T., Neural computing thermal comfort index for HVAC systems, Energy Conversion and Management., Vol. 46, No. 15-16 (2005), pp. 2553-2565.

Fayazbakhsh, M.A., Bahrami, M., Comprehensive modeling of vehicle air conditioning loads using heat balance method, SAE Technical Papers, 2013-01-1507 (2013), DOI:10.4271/2013-01-1507.

Jung, H., Modeling $\mathrm{CO}_{2}$ concentrations in vehicle cabin, SAE Technical Papers, 2013-01-1497 (2013), DOI:10.4271/2013-01-1497.

Khayyam, H., Kouzani, A.Z., Hu, E.J., Reducing energy consumption of vehicle air conditioning system by an energy management system, Proceeding of the 2009 Intelligent Vehicle Symposium (2009), pp. 752-757.

Khayyam, H., Kouzani, A.Z., Hu, E.J., Nahavandi, S., Coordinated energy management of vehicle air conditioning system, Applied Thermal Engineering, Vol. 31, No. 5 (2011a), pp. 750-764.

Khayyam, H., Nahavandi, S., Hu, E., Kouzani, A., Chonka, A., Abawajy, J., Marano, V., Davis, S., Intelligent energy management control of vehicle air conditioning via look-ahead system, Applied Thermal Engineering, Vol. 31, No. 16 (2011b), pp. 3147-3160.

Lee, H., Hwang, Y., Song, I., Jang, K., Transient thermal model of passenger car's cabin and implementation to saturation cycle with alternative working fluids, Energy, Vol. 90, Part 2 (2015), pp. 1859-1868.

Leephakpreeda, T., Thitipatanapong, R., Grittiyachot, T., Yungchareon, V., Occupancy-based control of indoor air ventilation, ScienceAsia, Vol. 27, No. 4 (2001), pp. 279-284.

Marcos, D., Pino, F.J., Bordons, C., Guerra, J.J., The development and validation of a thermal model for the cabin of a vehicle, Applied Thermal Engineering, Vol. 66, No. 1-2 (2014), pp. 646-656.

Mezrhab, A., Bouzidi, M., Computation of thermal comfort inside a passenger car compartment, Applied Thermal Engineering, Vol. 26, No. 14-15 (2006), pp. 1697-1704.

Ng, B.C., Darus, I.Z.M., Jamaluddin, H., Kamar, H.M., Dynamic modelling of an automotive variable speed air conditioning system using nonlinear autoregressive exogenous neural networks, Applied Thermal Engineering, Vol. 73, No. 1 (2014), pp. 1253-1267.

Torregrosa-Jaime, B., Bjurling, F., Corberan, J.M., Di Sciullo, F., Paya, J., Transient thermal model of a vehicle’s cabin validated under variable ambient conditions, Applied Thermal Engineering, Vol. 75 (2015), pp. 45-53.

Von Grabe, J., Potential of artificial neural networks to predict thermal sensation votes, Applied Energy, Vol. 161 (2016), pp. 412-424.

\section{Appendix}

Table A1 Weights and biases of artificial neural network for air-temperature prediction

\begin{tabular}{c|c|c|c|c|c|c|c|c|c|c}
\hline$j$ & 1 & 2 & 3 & 4 & 5 & 6 & 7 & 8 & 9 & 10 \\
\hline$w_{j, i=1}$ & -0.106 & 0.021 & 0.002 & -1.025 & 1.030 & -3.180 & 0.489 & 0.818 & -1.258 & -0.852 \\
$w_{j, i=2}$ & -1.227 & 0.008 & 0.0004 & -0.558 & -1.907 & 0.0001 & 0.001 & -0.001 & -0.817 & -0.001 \\
$w_{j, i=3}$ & -0.922 & -0.004 & -0.001 & 1.110 & 0.456 & -0.001 & -0.028 & 0.001 & -0.378 & 0.001 \\
$w_{j, i=4}$ & -1.317 & -0.021 & -0.002 & -0.111 & 0.706 & -0.001 & -0.073 & 0.001 & -1.088 & 0.004 \\
$w_{j, i=5}$ & -1.076 & -0.004 & -0.001 & 0.321 & 0.500 & -0.001 & -0.026 & 0.0004 & -0.440 & 0.002 \\
$w_{j, i=6}$ & -0.824 & -1.737 & -3.231 & -1.295 & 0.241 & -0.001 & 0.003 & -0.001 & 0.406 & 0.0001 \\
$w_{j, i=7}$ & 0.028 & -0.009 & -0.001 & -0.432 & 0.043 & -0.001 & -0.011 & -0.001 & 1.005 & -0.0002 \\
$w_{j, i=8}$ & 0.967 & 0.681 & 0.018 & 0.573 & -0.829 & 0.003 & 0.432 & -0.904 & -0.605 & -0.810 \\
$w_{j, i=9}$ & -0.739 & 1.725 & 0.213 & 0.248 & -0.939 & -2.235 & 0.796 & 0.018 & 0.786 & 0.013 \\
$w_{j, i=10}$ & -0.731 & -2.229 & 0.247 & 0.597 & 0.296 & -0.001 & -0.002 & -0.0001 & -0.012 & 0.0001 \\
$w_{j, i=11}$ & 0.117 & -0.001 & -0.001 & 0.963 & 0.025 & -4.453 & -0.001 & -0.0001 & -0.653 & 0.0001 \\
$w_{j, i=12}$ & 1.069 & 0.0007 & -0.001 & -1.043 & 1.465 & -0.001 & -0.007 & 0.0001 & -1.243 & 0.0004 \\
$w_{j, i=13}$ & -0.556 & 0.050 & 0.004 & 0.488 & 0.539 & 0.744 & 0.049 & -0.258 & 0.254 & 0.004 \\
$w_{j, i=14}$ & 0.439 & 2.507 & 1.988 & 1.539 & -0.085 & -0.001 & -0.037 & 0.0004 & 1.0002 & 0.001 \\
$w_{j, i=15}$ & -0.082 & 0.028 & 0.002 & -0.483 & 0.252 & 0.001 & 0.058 & -0.002 & 0.935 & -0.102 \\
$w_{j, i=16}$ & -0.415 & -0.001 & -0.001 & 0.157 & 0.139 & -0.001 & -0.004 & 0.001 & -0.999 & 0.0002 \\
\hline
\end{tabular}




\begin{tabular}{c|c|c|c|c|c|c|c|c|c|c}
\hline$j$ & 11 & 12 & 13 & 14 & 15 & 16 & 17 & 18 & 19 & 20 \\
\hline$w_{j, i=1}$ & -1.058 & 0.692 & 1.526 & -0.331 & -0.395 & -0.486 & 1.171 & -0.229 & 1.437 & -0.0001 \\
$w_{j, i=2}$ & -0.424 & 1.053 & -0.638 & -0.001 & -0.001 & -1.249 & -1.599 & -0.382 & 0.655 & 0.865 \\
$w_{j, i=3}$ & -0.589 & -0.592 & 0.525 & 0.023 & 0.015 & 0.643 & -0.126 & 0.081 & 0.979 & -0.0001 \\
$w_{j, i=4}$ & 0.516 & 1.148 & -0.215 & 0.059 & 0.040 & 1.897 & 0.236 & -0.363 & 1.373 & -0.0002 \\
$w_{j, i=5}$ & 1.260 & 1.194 & -0.413 & 0.021 & 0.014 & -0.413 & -0.277 & 0.650 & -0.186 & -2.151 \\
$w_{j, i=6}$ & 1.419 & -0.132 & -1.288 & -0.001 & -0.001 & -0.451 & -0.071 & 1.287 & -0.905 & -3.113 \\
$w_{j, i=7}$ & -0.244 & 0.558 & 0.036 & 0.009 & 0.006 & 0.775 & 0.214 & -0.572 & -0.161 & 3.142 \\
$w_{j, i=8}$ & -0.5019 & -0.844 & -0.901 & -0.368 & -0.254 & -0.222 & 1.460 & -1.017 & -0.855 & 3.369 \\
$w_{j, i=9}$ & 0.162 & 0.828 & -1.282 & -3.836 & 2.770 & 0.400 & 0.720 & 0.333 & 0.484 & 0.477 \\
$w_{j, i=10}$ & 0.479 & -1.193 & -1.129 & 0.002 & 0.001 & -0.412 & 0.014 & 1.017 & 1.374 & -2.519 \\
$w_{j, i=11}$ & -1.231 & 0.350 & -0.184 & 0.001 & 0.001 & -0.529 & -0.045 & 0.243 & -0.954 & -0.0001 \\
$w_{j, i=12}$ & -0.852 & 1.118 & 0.778 & 0.006 & 0.003 & -0.764 & -1.326 & 0.781 & 0.312 & 2.250 \\
$w_{j, i=13}$ & -0.234 & 0.589 & 1.113 & -0.041 & -0.026 & 0.609 & -0.723 & 0.141 & 0.056 & 1.784 \\
$w_{j, i=14}$ & 1.266 & -0.671 & 1.073 & 0.029 & 0.0201 & -0.156 & -0.158 & -1.660 & 0.154 & 1.406 \\
$w_{j, i=15}$ & 0.468 & 0.952 & -0.655 & -0.049 & -0.033 & -1.070 & -0.580 & -0.722 & 0.500 & 2.777 \\
$w_{j, i=16}$ & 0.728 & 0.255 & -0.395 & 0.003 & 0.002 & 0.167 & -0.410 & 0.566 & -0.806 & 5.868 \\
\hline
\end{tabular}

\begin{tabular}{c|c|c|c|c|c|c|c|c|c|c}
\hline$j$ & 1 & 2 & 3 & 4 & 5 & 6 & 7 & 8 & 9 & 10 \\
\hline$b_{j}$ & -3.493 & 2.327 & -3.384 & 2.457 & -2.091 & 5.264 & -2.563 & -1.754 & 0.746 & -0.355 \\
$w_{j}$ & -0.0001 & 0.009 & -0.111 & 3.168 & -0.001 & -1.222 & -4.279 & -3.348 & 0.0001 & -3.339 \\
\hline$j$ & 11 & 12 & 13 & 14 & 15 & 16 & 17 & 18 & 19 & 20 \\
\hline$b_{j}$ & -0.550 & 0.559 & 0.727 & 2.618 & -3.594 & -2.183 & 2.103 & 3.040 & 3.009 & -4.870 \\
$w_{j}$ & -1.550 & 3.934 & 2.649 & 3.810 & 5.808 & 3.575 & 5.832 & -3.204 & 0.0001 & 1.744 \\
\hline$b$ & \multicolumn{10}{|c}{0.7487} \\
\hline
\end{tabular}

